\title{
Predicting Creep Crack Initiation in Austenitic and Ferritic Steels using the Creep Toughness Parameter and Time Dependent Failure Assessment Diagram
}

\author{
Catrin M. Davies
}

Department of Mechanical Engineering, Imperial College London, South Kensington Campus, London SW7 2AZ.

\section{Abstract}

Methods for evaluating the creep toughness parameter, $K_{c}^{\text {mat }}$, are reviewed and $K_{c}^{\text {mat }}$ data are determined for a ferritic P22 steel from CCG tests on compact tension, $\mathrm{C}(\mathrm{T})$, specimens of homogenous parent material (PM) and heterogeneous specimen weldments at $565^{\circ} \mathrm{C}$ and compared to similar tests on austenitic $316 \mathrm{H}$ stainless steel at $550{ }^{\circ} \mathrm{C}$. Appropriate relations describing the time dependency of $K_{c}^{\text {mat }}$ are determined accounting for data scatter. Considerable differences are observed in the form of the $K_{c}^{\text {mat }}$ data and the time dependent failure assessment diagrams (TDFADs) for both the $316 \mathrm{H}$ and P22 steel. The TDFAD for P22 shows a strong time dependency but is insensitive to time for $316 \mathrm{H}$. Creep crack initiation $(\mathrm{CCl})$ times predictions are obtained using the TDFAD approach and compared to experimental results from $C(T)$ specimens and feature components. The TDFAD based on PM properties can be used to obtain conservative prediction of the $\mathrm{CCl}$ on the weldments. Conservative predictions are almost always obtained when lower bound $K_{c}^{\text {mat }}$ values are employed. Long term test are generally more relevant to industrial component lifetimes. The different trends between long and short term $\mathrm{CCl}$ time and growth data indicate that further long term test are required to further validate the procedure to predict the lifetimes of high temperature component lifetimes.

\section{Keywords}

TDFAD, Creep Toughness, Creep Crack Initiation (CCI), 316H Steel, P22 Steel, Weldments.

\section{Nomenclature}

$\begin{array}{ll}a, \Delta a & =\text { Crack length, Crack extension } \\ \dot{a} & =\text { Crack growth rate } \\ A & =\text { Creep strain rate coefficient } \\ A_{p} & =\text { Primary creep strain coefficient } \\ B_{n} & =\text { Specimen net section thickness between side-grooves } \\ B_{r} & =\text { Coefficient in the stress rupture time law } \\ C^{*} & =\text { Steady state creep characterising fracture mechanics parameter } \\ \mathrm{CCG} & =\text { Creep crack growth } \\ \mathrm{CCl} & =\text { Creep crack initiation } \\ D & =\text { Constant coefficient in creep crack growth rate correlation with } C^{*} \\ D_{i} & =\text { Constant coefficient in creep crack initiation time correlation with } C^{*} \\ E & =\text { Elastic (Young's) modulus } \\ E^{\prime} & =\text { Effective elastic modulus } \\ H & =\text { Correlating coefficient in the } K_{\text {mat }}^{c} \text { vs. time relation } \\ \mathrm{HAZ} & =\text { Heat affected zone } \\ J & =\text { Elastic-Plastic fracture mechanics parameter }\end{array}$




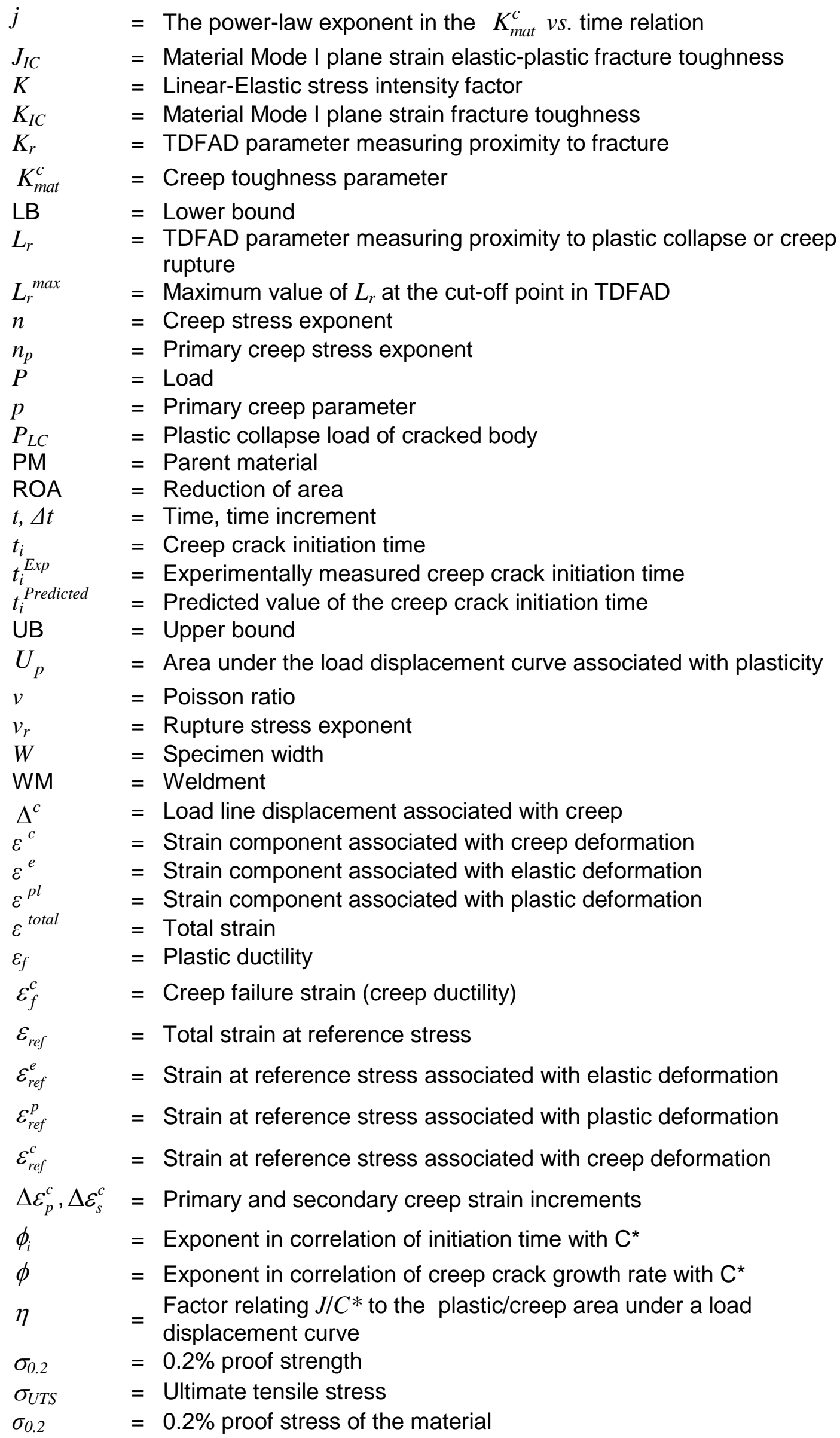


$\sigma_{0.2}^{c}=0.2 \%$ creep strength (stress at $0.2 \%$ inelastic strain)

$\sigma_{\text {flow }} \quad=$ Flow stress $\left(\sigma_{\text {UTS }}+\sigma_{0.2}\right) / 2$

\section{Introduction}

The lifetime of components operating in high temperature plant is limited by the mechanisms of creep crack initiation (CCl) and growth (CCG). The CCI time is the period of time prior to the onset of crack extension from an existing defect due to creep crack growth and can occupy large fraction ( $>80 \%$ ) of a components service lifetime ${ }^{1}$. The $\mathrm{CCl}$ time is generally defined as the time for a defined small measureable crack extension, typically $0.2 \mathrm{~mm}$ for laboratory specimens or $0.5 \mathrm{~mm}{ }^{2}$. Reliable predictions of $\mathrm{CCl}$ time are fundamental in high temperature component lifetime assessments due to the duration of the $\mathrm{CCl}$ period.

The time dependant failure assessment diagram (TDFAD) approach has become increasingly recognised for the prediction of creep crack initiation (CCI) times ${ }^{3}$. The development of the TDFAD has mainly been based on austenitic type $316 \mathrm{H}$ stainless steel which differs from ferritic steels in their tensile and creep material behaviour and further verification are required before the procedure may be recommended for ferritic steels ${ }^{4,5}$. Two widely used alloys for high-temperature plant components with contrasting properties are ferritic P22 (21/4Cr1Mo) steel and austenitic type $316 \mathrm{H}$ stainless steel. The favourable qualities of these steels include high creep ductility and relatively high weldability ${ }^{6,7}$. These two steels are considered here in the evaluation of the TDFAD method.

The TDFAD approach for $\mathrm{CCl}$ time predictions relies on the availability of reliable creep toughness $\left(K_{m a t}^{c}\right.$ ) data. The main advantage of the TDFAD approach is that detailed calculations of crack tip parameters such as $C^{*}$ are not required and that the TDFAD can indicate whether failure is controlled by crack growth, creep rupture or plastic collapse i.e. the fracture regime need not be specified in advance. Methods for evaluation or estimating the $K_{m a t}^{c}$ parameter have been developed and modified over recent years.

A considerable amount of creep toughness data has been determined for austenitic type $316 \mathrm{H}$ stainless steel in the region of $500-700^{\circ} \mathrm{C}$, though mainly at $550^{\circ} \mathrm{C}^{8,9}$. Limited $K_{\text {mat }}^{c}$ data have also been determined for a range of ferritic steels $4,5,8,10-12$, and in some cases TDFADs have also been produced. Creep toughness data often show appreciable scatter ${ }^{8,9}$ which must be considered when obtaining $\mathrm{CCl}$ time predictions. In the majority of cases, where TDFADs have been determined together with creep toughness data, explicit $\mathrm{CCl}$ times have not been obtained. Generally, the CCI data for a given crack extension have been plotted on a TDFAD for a range of times and an assessment made to determine if the TDFAD approach leads to conservative predictions, or sometimes a range of $\mathrm{CCl}$ times indicated. The degree of conservatism/non-conservatism however, is not indicated. 
Considerably high loads are often applied to specimens in CCG tests, leading to relatively short test durations compared to the lifetimes of high temperature components operating in plants. Therefore, the application of methods based on CCG test data to predict real component lifetimes require validation ${ }^{4}$. Components are often welded and the application of the TDFAD approach for weldments has been considered ${ }^{12-16}$. However, a number of complications arise when considering weldments such as material mis-match effects which may require consideration.

In previous work ${ }^{9}$, the TDFAD approach has been applied to predict $\mathrm{CCl}$ times in austenitic type $316 \mathrm{H}$ stainless steel at $550^{\circ} \mathrm{C}$, and the sensitivity of predictions to creep toughness data bounds and reference stress solutions have been examined. In this work methods for $K_{m a t}^{c}$ evaluation and estimation are reviewed and $K_{m a t}^{c}$ data are determined for a ferritic P22 steel from CCG tests on compact tension, C(T), specimens of homogenous parent material and heterogeneous specimen weldments at $565{ }^{\circ} \mathrm{C}$. The weldments consist of parent material (PM), weld metal and a heat affected above (HAZ). The crack tip is located on the HAZ/PM boundary where cracking is often observed in practice. Appropriate relations describing the time dependency of $K_{m a t}^{c}$ are determined accounting for data scatter. The TDFAD diagram and its associated parameters are then compared for the austenitic type $316 \mathrm{H}$ and ferritic P22 steel. The influence of test duration, and material condition are also considered and $\mathrm{CCl}$ time predictions obtained and compared to experimental results from short and long term laboratory tests specimens and feature components.

\section{The Failure Assessment Diagram (FAD) Approach}

The FAD procedure considers that failure will occur by plastic collapse or brittle/ductile fracture. The proximity to failure by fracture and plastic collapse are measured by the parameters $K_{r}$ and $L_{r}$, respectively, defined by

$$
\begin{gathered}
K_{r}=\frac{K}{K_{I C}}=\left(\frac{K^{2}}{E^{\prime} J_{I C}}\right)^{\frac{1}{2}} \\
L_{r}=\frac{\sigma_{r e f}}{\sigma_{0.2}}=\frac{P}{P_{L C}}
\end{gathered}
$$

where $K_{I C}$ and $J_{I C}$ are fracture toughness values (critical values of $K$ and $J$ for fracture under Mode I, tensile loading), $E^{\prime}$ the effective elastic modulus (equal to $E$ for plane stress or $E /\left(1-v^{2}\right)$ for plane strain conditions where $v$ is the Poisson ratio). In Eqn (2) $\sigma_{r e f}$ is the reference stress ${ }^{1}$ of a geometry, $\sigma_{0.2}$ is the $0.2 \%$ proof stress (measure of the materials yield stress), $P$ the applied load and $P_{L C}$ the collapse load of the cracked geometry ${ }^{1}$.

The R6 Option 1 curve ${ }^{17,18}$ is material independent and defined by

$$
K_{r}=\left(1-0.14 L_{r}^{2}\right)\left[0.3+0.7 \exp \left(-0.65 L_{r}^{6}\right)\right] \text { for } L_{r} \leq L_{r}^{\max }
$$




$$
K_{r}=0 \text { for } L_{r}>L_{r}^{\max }
$$

The cut-off, $L_{r}{ }^{\max }$, which indicates failure by plastic collapse is defined by the ratio

$$
L_{r}^{\max }=\frac{\sigma_{\text {flow }}}{\sigma_{0.2}}
$$

where $\sigma_{\text {flow }}$ is the mean of the ultimate tensile stress, $\sigma_{U T S}$, obtained from the engineering stress-strain curve and the $0.2 \%$ proof stress i.e. $\sigma_{\text {flow }}=\left(\sigma_{U T S}+\sigma_{0.2}\right) / 2$

The R6 Option 2 FAD has a material specific failure assessment curve (FAC) which has been derived based on the assumption that crack growth occurs when the $J$-Integral attains a critical value.

\subsection{The Time Dependent Failure Assessment Diagram (TDFAD)}

The R6 Option 2 FAD has been extended to a time dependent failure assessment diagram (TDFAD) which addresses limited high temperature crack growth ${ }^{3}$. This is done by replacing $K_{I C}$, in Eqn (1) by a creep toughness corresponding to a given crack extension at a given time, denoted $K_{\text {mat }}^{c}(\Delta a, t)$, and $\sigma_{0.2}$ in Eqn (2) by the $0.2 \%$ inelastic (creep and plastic) strain from an isochronous stress-strain curve at a particular time and temperature, $\sigma_{0.2}^{c}$, also called the $0.2 \%$ creep strength. The value of $\sigma_{0.2}^{c}$ will decrease as time increases i.e. creep strain increases. In the TDFAD, for the case of a single primary load, the parameters $K_{r}$ and $L_{r}$ are therefore defined as

$$
\begin{gathered}
K_{r}=\frac{K}{K_{m a t}^{c}} \\
L_{r}=\frac{\sigma_{r e f}}{\sigma_{0.2}^{c}}
\end{gathered}
$$

The cut off point $L_{r}^{\max }$ is defined on the TDFAD as

$$
L_{r}^{\max }=\frac{\sigma_{r}}{\sigma_{0.2}^{c}}
$$

where $\sigma_{r}$ is the stress to cause creep rupture at the same time as $\sigma_{0.2}^{c}$ is evaluated. If $L_{r}$ exceeds $L_{r}^{\max }$, failure is expected to occur by creep rupture rather than by fracture. In order to be consistent with the R6 procedure, $L_{r}^{\max }$ in the TDFAD should not exceed the value of $L_{r}^{\max }$ defined in Eqn (5). The time to rupture in a uniaxial creep test over a range of stresses can often be approximated by the power-law relation,

$$
t_{r}=B_{r} \sigma^{-v_{r}}
$$

where $B_{r}$ and $v_{r}$ are the rupture coefficient and exponent, respectively.

The time dependent failure assessment curve is based on the assumption that crack growth occurs when the dependent time parameter, $J(t)$, attains a critical value. A failure assessment diagram for a specific time is defined by the equations 


$$
\begin{gathered}
K_{r}=\left[\frac{E \varepsilon_{r e f}}{L_{r} \sigma_{0.2}^{c}}+\frac{L_{r}^{3} \sigma_{0.2}^{c}}{2 E \varepsilon_{r e f}}\right]^{-1 / 2} \text { for } L_{r} \leq L_{r}^{\max } \\
K_{r}=0 \text { for } L_{r}>L_{r}^{\max }
\end{gathered}
$$

In Eqn (10) $\varepsilon_{r e f}$ is the total strain at reference stress at a given time, given by the sum of the elastic and plastic strain and the total creep strain accumulated in that time i.e.

$$
\varepsilon_{\text {ref }}(t)=\varepsilon_{\text {ref }}^{e}+\varepsilon_{\text {ref }}^{p}+\varepsilon_{\text {ref }}^{c}(t)
$$

Note that $\varepsilon_{r e f}$ is the true strain at true stress $\sigma_{r e f}\left(=L_{r} \sigma_{0.2}\right)$ (and not the engineering strain). Note also that at short times $\varepsilon_{\text {ref }}(t) \approx \varepsilon_{\text {ref }}^{e}+\varepsilon_{\text {ref }}^{p}$ and $\sigma_{0.2}^{c} \approx \sigma_{0.2}$, and Eqn (10) reduces to the $\mathrm{R} 6$ Option 2 curve. At long times $\varepsilon_{\text {ref }}(t) \approx \varepsilon_{\text {ref }}^{c}$ and Eqn (10) reduces to

$$
K_{r}=\left[\frac{E \varepsilon_{r e f}^{c}}{\sigma_{r e f}}\right]^{-1 / 2}
$$

Equation (13) can be derived for steady state creep conditions, where the creep strain rate is a constant, based on the assumption that at long times $J(t)$, evaluated, can be approximated by the product of $C^{*}$ and time (i.e. $J(t) \approx C^{*} t^{19}$ ) and $C^{*}$ is given by the reference stress estimate ${ }^{1}$. The TDFAD can therefore measure the proximity to failure by fast fracture, creep crack growth, plastic collapse and creep rupture. Therefore, in the TDFAD approach, a failure mode does not have to be pre-defined.

\subsection{Application of TDFAD to Predict Creep Crack Initiation (CCl)}

The TDFAD can be used to predict if a crack will extend a distance $\Delta a$ in a given time or the time required for a specified amount of crack extension. Since $\mathrm{CCl}$ can be defined as the period of time required for a small increment of crack growth, $\Delta a$, the TDFAD may be used to predict $\mathrm{CCl}$ times. For some materials the curves may not vary greatly with time and curves for longer times can be used to provide a conservative TDFAD for an assessment at shorter times ${ }^{8}$.

To predict $\mathrm{CCl}$ an initial time estimate is made and the values of $L_{r}$ and $K_{r}$, and their associated parameters, are determined for the specified initiation distance, $\Delta a$, at that time. The point $\left(L_{r}, K_{r}\right)$ is then plotted on the TDFAD. If the point lies within the TDFAD then the crack extension is less than $\Delta a$ and creep rupture is avoided in the assessment time. To determine an initiation time, $t_{i}$, a time locus of points $\left(L_{r}, K_{r}\right)$ is constructed at various times. The time for a crack extension $\Delta a$ is given by the intersection of a point on this locus (for a given time) with the failure assessment curve for the corresponding time. An iterative process is required to match the times associated with the point of intersection of the locus and the TDFAD constructed. The procedure is further detailed in ${ }^{8,9}$. 


\subsection{Isochronous Stress-Strain Data}

Isochronous stress-strain curves for the specified temperature are required in order to determine $\sigma_{0.2}^{c}$ and the overall TDFAD. Isochronous stress-strain data are generated here using the elastic-plastic and creep material response. The method used follows the procedure in the RCC-MR design code ${ }^{20}$ for primary-secondary creep of Type 316 stainless steel material. Thus, the primary and secondary creep strain increments, $\Delta \varepsilon_{p}^{c}$ and $\Delta \varepsilon_{s}^{c}$, are calculated according to

$$
\begin{gathered}
\Delta \varepsilon_{p}^{c}=p A_{p}^{1 / p} \sigma^{n_{p} / p} \varepsilon^{(1-1 / p)} \Delta t \\
\Delta \varepsilon_{s}^{c}=A \sigma^{n} \Delta t
\end{gathered}
$$

The creep strain increment, $\Delta \varepsilon^{c}$, is equal to the larger of the two increments calculated from Eqns (14) and (15) i.e.

$$
\Delta \varepsilon^{c}\left\{\begin{array}{l}
\Delta \varepsilon_{p}^{c} \text { for } \Delta \varepsilon_{p}^{c} \geq \Delta \varepsilon_{s}^{c} \\
\Delta \varepsilon_{s}^{c} \text { for } \Delta \varepsilon_{p}^{c}<\Delta \varepsilon_{s}^{c}
\end{array}\right.
$$

The primary and secondary creep constants in Eqns (14) and (15) are given in Table 1 for $316 \mathrm{H}$ stainless steel at $550^{\circ} \mathrm{C}$ and P22 steel at $565^{\circ} \mathrm{C}$. For a particular time, the total strain at any stress level is given by the sum of the elastic and plastic strain and the total creep strain accumulated in that time, i.e.

$$
\varepsilon^{\text {total }}(\sigma, t)=\varepsilon^{e}(\sigma)+\varepsilon^{p l}(\sigma)+\sum_{t} \Delta \varepsilon^{c}(\sigma, \Delta t)
$$

\section{Evaluation of the Creep Toughness Parameter, $K_{m a t}^{c}$}

The $K_{\text {mat }}^{c}$ parameter is evaluated from the load displacement curve generated during a CCG test using the relation ${ }^{3,8}$.

$$
K_{m a t}^{c}=\left(K^{2}+\frac{E^{\prime} U_{p}}{B_{n}(W-a)} \eta+\frac{n}{n+1} \frac{E^{\prime} P \Delta^{c}}{B_{n}(W-a)} \eta\right)^{1 / 2}
$$

where $U_{p}$ is the area under the load displacement curve associated with plasticity, $W$ is the specimen width, $B_{n}$ is the net specimen thickness between any side-grooves, $a$ is the crack length and $n$ the secondary creep power-law stress exponent (see Eqn (15)) and $\eta$ a geometry function $\left(\eta=2.2\right.$ for $\mathrm{C}(\mathrm{T})$ specimens $\left.{ }^{21}\right)$. Note that the $K_{\text {mat }}^{c}$ relation has been modified since the work in ${ }^{9}$.

In the absence of specimen load-displacement data a method has been proposed to estimate $K_{\text {mat }}^{c}$ from $\mathrm{CCl}$ and CCG data. Under steady state conditions the CCG rate, $\dot{a}$, may be described by the expression ${ }^{2}$

$$
\dot{a}=D C * \phi
$$


where $D$ and $\phi$ are temperature dependent crack growth constants. The $\mathrm{CCl}$ time may also be described by the $C^{*}$ parameter according to the power-law relationship

$$
t_{i}=D_{i} C^{*-\phi_{i}}
$$

where $D_{i}$ and $\phi_{i}$ are temperature dependent CCl constants. Assuming widespread creep conditions, a constant secondary creep strain rate and using the reference stress estimate of $C^{*}{ }^{1}$, it can be shown that $K_{\text {mat }}^{c}$ may be estimated from $\mathrm{CCl}$ data according to the relation ${ }^{22}$

$$
K_{c}^{m a t} \approx\left(E D_{i}^{1 / \phi_{i}} t^{\left(1-1 / \phi_{i}\right)}\right)^{1 / 2}
$$

Alternatively, if crack growth is assumed a continuous process commencing at zero time, then $K_{\text {mat }}^{c}$ may be estimated from CCG data ${ }^{22}$ using

$$
K_{c}^{m a t} \approx\left(E\left(\frac{\Delta a}{D}\right)^{1 / \phi} t^{1-1 / \phi}\right)^{1 / 2}
$$

It can therefore be seen from Eqn (22) that $K_{\text {mat }}^{c}$ is expected to decrease with time according to

$$
K_{c}^{m a t} \alpha\left(t^{1-1 / \phi}\right)^{1 / 2}
$$

Creep crack initiation and growth models ${ }^{23-25}$ predict that $\phi_{i}=\phi=n /(n+1)$ thus, substituting for $\phi$ in Eqn (23) it may be written

$$
K_{c}^{m a t} \alpha t^{-1 / 2 n}
$$

It is therefore expected that $K_{c}^{\text {mat }}$ follows the power-law relationship

$$
K_{c}^{m a t}(\Delta a, t)=H t_{i}^{-j}
$$

where $H$ is the correlating coefficient and, $j$ is the power-law exponent.

\section{Creep Deformation and CCG Behaviour of P22 and 316H Steel}

Firstly, the high temperature tensile and creep deformation and rupture behaviour of the two materials are compared to reveal their differences, which will be reflected in the form of their TDFADs. The true-stress $v s$. true-strain curves of both materials are shown in Figure 1 up to the point in the tests where a failure mechanism intervened. The tensile properties are given in Table 1. The shape of the tensile behaviour of P22 and $316 \mathrm{H}$ are clearly different. The $0.2 \%$ proof stress of $\mathrm{P} 22$ is almost $70 \%$ higher than that of $316 \mathrm{H}$ and exhibits relatively little hardening. On the contrary, $316 \mathrm{H}$ has a high degree of work hardening and has a $10 \%$ higher plastic ductility, $\varepsilon_{f}$, than P22 steel, based on engineering strain (Eng) values.

The secondary creep strain rate and rupture-time $v s$. stress relations for the two steels are compared in Figure 2(a) and (b), respectively. Note that the stress values for $316 \mathrm{H}$ are true-stress values accounting for plastic strain on loading. However, in the absence of loading data, and since the applied stress are significantly less than 
the $\sigma_{0.2}$ of the steel (thus little plastic strain is expected on specimen loading), the engineering stress has been used for the P22 tests. In Figure 2(a) the stress to cause a given strain rate or rupture time is around a factor of three higher for $316 \mathrm{H}$ than P22. The creep strain rates for a given stress are therefore significantly higher, and rupture times lower, for $\mathrm{P} 22$ steel in comparison to $316 \mathrm{H}$ at these temperatures. The uniaxial creep failure strain (creep ductility), $\varepsilon_{f}^{c}$, of P22 is over twice that of $316 \mathrm{H}$ based on both axial and reduction of area (ROA) measurements (see Table 1).

\subsection{Isochronous Stress Strain Curves}

The materials tensile data and creep laws have been combined to generate isochronous stress-strain curves as specified in Section 2.3 using the material properties given in Table 1. The resultant curves are very different for the $316 \mathrm{H}$ and P22 steel as shown in Figure 3(a) and (b), respectively, for times up to 100,000 hours. The P22 steel's curves are strongly time dependent even at short times. In fact the P22 curve for a time of one hour almost overlays the $316 \mathrm{H}$ curve at 100,000 hours. The corresponding $0.2 \%$ inelastic (creep and plastic) strain, $\sigma_{0.2}^{c}$, are illustrated and compared in Figure 4. Little change in $\sigma_{0.2}^{c}$ for $316 \mathrm{H}$ steel is observed for the first 1000 hrs whilst creep strains dominate in the P22 steel. Even at very short times it can be seen that for $\mathrm{P} 22 \sigma_{0.2}^{c}$ reduces by $50 \%$ due to creep strain accumulation in the first hour alone.

\section{Creep Fracture Behaviour}

\subsection{CCG Behaviour}

Creep crack growth test data on the compact tension specimen, $\mathrm{C}(\mathrm{T})$, from ${ }^{26}$ for P22 and ${ }^{27,28}$ for $316 \mathrm{H}$ steel have been re-analysed in accord with recent changes in data analysis procedures ${ }^{2,3}$. A sizable data set is available for $316 \mathrm{H}$ with test durations ranging between 100 and 18,000 hours. The CCG tests on P22 steel were relatively short ranging between 300 and 4,400 hrs. The significance of plasticity on loading of the $316 \mathrm{H}$ steel specimens and it's influence on CCG behaviour has been described in 9, 29, 30. The P22 test load-up data was not available for analysis. However, it is expected that there is little plasticity on loading of P22 specimens since the ratio $\sigma_{\text {ref }}$ $/ \sigma_{0.2}$, on load up is less than 0.5 for all specimens and is on average 0.31 and 0.45 assuming plane strain and plane stress conditions, respectively. For the $316 \mathrm{H}$ specimens this ratio was close to or exceeded unity assuming plane strain conditions, except for the long term tests where the ratio was approximately 0.78 .

Mean line power-law regression fits have been made to the CCG data as shown in Figure 5. Upper bound (UB) and lower bound (LB) fits are obtained by offsetting the mean line by \pm 2 standard deviations (s.d.) of the regression fit, assuming a constant slope. Separate fits have been made to the long and short term tests of $316 \mathrm{H}$ in Figure 5(a) due to the distinct CCG behaviour observed in the long term tests, where plasticity is limited and thus high specimen constraint effects maintained ${ }^{30}$. The CCG rate constants for these fits (see Eqn (5)) are given in Table 2 Similar CCG behaviour 
is exhibited by both steels for $C^{*}>1 \times 10^{-5} \mathrm{MPamh}^{-1}$, however significant tails are observed for $\mathrm{P} 22$ though the validity criterion ${ }^{2}$ are met.

\subsection{CCl Behaviour}

The $\mathrm{CCl}$ times for $0.2 \mathrm{~mm}$ and $0.5 \mathrm{~mm}$ of crack extension are plotted against the experimentally determined $C^{*}$ parameter at the corresponding time in Figure 6 and Figure 7 for $316 \mathrm{H}$ and P22 steel, respectively. Regression fits have been made to the data and the constants in Eqn (20) determined, accounting for the degree of data scatter (see Table 3). The $\mathrm{CCl}$ time data for $316 \mathrm{H}$ (Figure 6) appear to form reasonable correlations with the $C^{*}$ parameter, though the power-law correlation exponent, $\phi_{i}$, is significantly less than $n /(n+1)$ as predicted from $\mathrm{CCl}$ models ${ }^{25,29}$. The value of $\phi_{i}$ obtained from the regression fit for P22 data for $\Delta a=0.2 \mathrm{~mm}$ is greater than unity indicating that the experimentally determined $C^{*}$ parameter is not an appropriate correlating parameter in this case since, as indicated by the tails shown in Figure 5, steady state CCG conditions have not been achieved ${ }^{2}$. Also, since the data set for P22 is relatively small it can be difficult to establish the data trend. More reasonable correlating parameter are obtained for the P22 data at $\Delta a=$ $0.5 \mathrm{~mm}$, though again $\phi_{i}$ is significantly less than $n /(n+1)$. A significant degree of data scatter is observed for both materials, quantified by the UB/LB values of $D_{i}$, which are generally a factor of 5 greater or less than the mean value, respectively.

\subsection{Creep Toughness Data, $K_{c}^{\text {mat }}$}

The $K_{c}^{\text {mat }}$ values at $\Delta a=0.2$ and $0.5 \mathrm{~mm}$ of crack extension have been calculated using Eqn (18) for both materials in homogenous parent material (PM) and weldment (WM) conditions. A regression fit has been made to the data to obtain the values of $H$ and $j$ in Eqn (25) and again UB/LB fits made by offsetting the mean by \pm 2 s.d. of the data set (see Table 4 and Table 5). In addition, the best line fit has been made to the data assuming a slope of $1 /(2 n)$ as predicted in Eqn (24). Note that sensible trendlines have not been obtained using Eqns (21) and (22) in conjunction with the CCG and CCI regression data detailed in Table 2 and Table 3 , respectively, and thus are not shown in the following figures.

\subsubsection{Homogenous Parent Material (PM) $K_{c}^{\text {mat }}$ Data}

The creep toughness data of $316 \mathrm{H} \mathrm{PM}$ at $565^{\circ} \mathrm{C}$ has previously been presented in ${ }^{9}$, 31-33. However, this data has been re-analysed here for consistency, and to be in accord with recent modifications in the $K_{c}^{\text {mat }}$ evaluation procedure. The slope $j$ of the regression fits to the $316 \mathrm{H}$ data in Figure 8, is a factor of 5 steeper than predicted using Eqn (24). The best fit line to the data using Eqn (24) provides a reasonable fit to the data for less than $500 \mathrm{hrs}$ and $800 \mathrm{hrs}$ for $\Delta a=0.2$ and $0.5 \mathrm{~mm}$, respectively. For times greater than these, a change in the data trend can be observed.

The corresponding $K_{c}^{\text {mat }}$ data for PM P22 steel are presented in Figure 9. Creep toughness data for $\mathrm{P} 22$ steel at $550{ }^{\circ} \mathrm{C}$ has been presented in ${ }^{12} . K_{c}^{\text {mat }}$ is expected to be insensitive to such small variations in temperature ${ }^{8}$, thus the data in ${ }^{12}$ at $550{ }^{\circ} \mathrm{C}$ 
has been combined with the data analysed here at $565{ }^{\circ} \mathrm{C}$. The influence of temperature on $K_{c}^{\text {mat }}$ is further discussed for materials of similar compositions to those analysed here in ${ }^{10}$.

The regression fit values for $\Delta a=0.2 \mathrm{~mm}$ were non-sensible as the negative $j$ value in Table 4 indicates an increase in $K_{c}^{\text {mat }}$ with time. For $\Delta a=0.5 \mathrm{~mm}$, however, $j \approx 1 /(2 n)$ as predicted in Eqn (24). For the P22 data therefore the mean lines shown in Figure 9 are the best fits of Eqn (24) to the data set, and the UB/LB factors are assumed to be equal to that obtained from a regression fit to the data.

\subsubsection{Comparison of Parent and Weldment Data}

The creep toughness data of 316 steel compact tension specimen weldments have been determined and compared to PM data in ${ }^{16}$ where full details of the weldment geometry can be found. This weldment data is compared to additional and reanalysed PM data in Figure 10. Due to the limited amount of weldment data available the slope of the weldment trend line fitted to the data has been assumed to be equal to that of the regression fit to the PM. A relatively good fit is observed, the coefficients for which are given in Table 4. For a given time, the mean $K_{c}^{\text {mat }}$ value of the 316 weldment specimens is a factor of approximately 2 less than that for a PM.

Creep toughness data from $\mathrm{C}(\mathrm{T})$ weldment specimens of $\mathrm{P} 22$ steel are compared to PM specimens at $565{ }^{\circ} \mathrm{C}$ and $550{ }^{\circ} \mathrm{C}$ for both $\Delta a=0.2$ and $0.5 \mathrm{~mm}$ in Figure 11 (a) and (b), respectively. The PM and weldment data at both temperatures fall within the same scatter bands. A best fit line assuming a slope $j=1 /(2 n)$, as in Eqn (24), has been made to the PM and weldment data sets, where $n$ has been taken to be equal to the PM value. This assumption is justified by the fact that the value of $n$ determined from tests performed on cross-weld uniaxial specimens of P22 at $550{ }^{\circ} \mathrm{C}$, which are considered to most represent the behaviour of $\mathrm{C}(\mathrm{T})$ weldments, were found equal to the PM test values ${ }^{26}$. Note that sensible regression fits were not obtained for this data set. On average there is a $10 \%$ difference between the PM and weldment value of $K_{c}^{\text {mat }}$ for a given time and bound, whereas there is around a $40 \%$ and $80 \%$ difference between the UB or LB and mean value of $K_{c}^{\text {mat }}$ for a given time, for the PM and weldment data, respectively, as can be deduced from Table 5 . Therefore, within the extent of data scatter, little difference in creep toughness behaviour is observed between the two material conditions, for the P22 steel.

\section{TDFAD Formation}

The TDFADs for a range of times $(t=0,1,10,100,1000,10000$ and $100000 \mathrm{hrs})$ have been determined from Eqn (10),(11), (14)-(17), using the PM data given in Table 1, and are shown in Figure 12. Also shown in Figure 12 for comparison purposes is the R6 Option 1 curve (see Eqn (3)). Note that the R6 cut off point, $L_{r}^{\max }$ (see Eqn (5)) is the appropriate value to use (see Section 2.1) for times less than $10,000 \mathrm{hrs}$ for the $316 \mathrm{H}$ material and for all times in the case of P22.

As can be seen in Figure 12(a) and described in ${ }^{9}$ the $316 \mathrm{H}$ TDFAD is insensitive to time and deviates little from the R6 option 1 curve. The P22 TDFAD however, is in 
relatively good agreement with the $\mathrm{R} 6$ Option 1 curve at time $0 \mathrm{hrs}$, but almost instantly deviates significantly from it. These trends are due to the relatively low and very high creep strain rates experienced in $316 \mathrm{H}$ and P22, respectively, (see Figure 2(a) and Figure 3) at these temperatures.

\section{CCI Time Predictions}

The TDFAD procedure for predicting $\mathrm{CCl}$ times is evaluated for both steels. A program has been developed that determines the intersection of a point $\left(K_{r}, L_{r}\right)$ for a given time and crack extension with the TDFAD of corresponding time. Predictions for both PM and weldment data have been determined, though note the TDFADs have strictly been derived from PM data. The CCI times have been predicted for the tests on homogenous PM and weldment $C(T)$ specimens ${ }^{16,21,27}$. These tests have been used to derive the relationship of creep toughness on time, thus appropriate predictions are expected. In addition, CCI data are available for feature tests on P22 PM and weldment pipe components, as detailed in ${ }^{34}$. These results are also predicted here using the TDFAD procedure. Predictions on $\mathrm{C}(\mathrm{T})$ specimens have been based on the plane strain reference stress solution. Details of the stress intensity factor and reference stress solution for the pipe component are given in ${ }^{34}$.

The TDFADs predicted $\mathrm{CCl}$ time, $t_{i}^{\text {Predicted }}$, is compared to the experimentally determined value, $t_{i}^{E x p}$, in Figure 13-Figure 15. Included in these figures is the line for $t_{i}^{\text {Predicted }}=t_{i}{ }^{\text {Exp }}$. Points situated below this line indicate a conservative prediction, and vice-versa. Predictions have been obtained using the mean and LB values of $K_{c}^{\text {mat }}$ calculated using Eqn (25) with the regression fit values shown in Table 4 for $316 \mathrm{H}$ and the best fit values with an assumed slope of $j=1 /(2 n)$ (see Eqn (24)) as shown in Table 5 for the P22 material. The predictions based on mean or LB $K_{c}^{\text {mat }}$ values are shown as open and grey symbols, respectively.

The weldment and PM specimen predictions are shown together in Figure 13 for the 316 steel. Similar trends are observed for the two material conditions at both $\Delta a=0.2$ and $0.5 \mathrm{~mm}$. Predictions based on mean $K_{c}^{\text {mat }}$ values are often, but not always, conservative whereas the use of LB $K_{c}^{\text {mat }}$ values consistently gives conservative predictions. The same is true for $\mathrm{C}(\mathrm{T})$ specimen $\mathrm{PM}$ and weldment data for P22 material shown in Figure 14 and Figure 15, respectively, except for one point in Figure 14(b) and Figure 15(a) which is just above the line using a LB $K_{c}^{\text {mat }}$ value. However, since the data set available for P22 is limited, less confidence can be assigned to the appropriateness of the TDFAD for predicting CCI for P22, especially for long term conditions since long term data are unavailable for this material.

An initiation distance $\Delta a=0.5 \mathrm{~mm}$ has been deemed suitable for the feature components ${ }^{34}$, thus pipe data are not included in Figure 14(a) and Figure 15(a). Predictions for the pipe components are found to be very conservative in all cases with $t_{i}^{\text {Predicted }}$ predicted being less than $5 \%$ of $t_{i}^{E x p}$. The degree of uncertainty associated with $t_{i}{ }^{\operatorname{Exp}}$ measurements and due to the approximations made in evaluating the parameters $K$ and $\sigma_{\text {ref }}$ for these components leads to higher 
uncertainties in their $\mathrm{CCl}$ time predictions compared to that for laboratory test specimens. These additional uncertainties may contribute to the excessive conservatism in the $\mathrm{CCl}$ times predicted for these components. This uncertainty is however not easily quantified. The influence of the reference stress solution on the $\mathrm{CCl}$ predictions has previously been examined and discussed in ${ }^{9}$.

\section{Discussion}

The appropriate isochronous stress-strain response of a location being either within the parent, weld or HAZ of a weldment will be affected by the isochronous stressstrain response of the surrounding material region. An equivalent isochronous stressstrain response may be defined, with intermediate isochronous properties, which will be a function of weldment geometry, loading, crack geometry, size and location. Note that for the weldment tests considered in this work the crack was located in the HAZ adjacent to the HAZ/PM interface. The equivalent isochronous stress-strain curve is based on the mis-match limit load and equivalent material stress-strain curve described in $\mathrm{R} 6{ }^{17}$. A conservative assessment is however obtained using the tensile properties of the weaker material, which would be the $316 \mathrm{H}$ parent material in the case of the 316 specimen weldments which consist of $316 \mathrm{H} \mathrm{PM}$ and $316 \mathrm{~L}$ weld metal ${ }^{16}$. The mis-match reference stress for an overmatched weld is expected to be greater than that for a homogeneous specimen (see e.g. ${ }^{35}$ ). Thus, should a conservative prediction be obtained for an overmatched weldment using the materials PM properties and a homogeneous reference stress solution then the use of the mismatch reference stress would further increase the degree of conservatism. Tensile test data are not available for the P22 weld material at $565{ }^{\circ} \mathrm{C}$ however results in ${ }^{36}$ from a similar weld tested at $550{ }^{\circ} \mathrm{C}$ indicates that the welds yield strength is slightly $(7 \%)$ less than the $\mathrm{PM}$, however their general stress-strain behaviour of the weld is very similar to that of the PM. Therefore, it is considered that mismatch effects may not be significant for the P22 weldments analysis. The influence of mismatch on the isochronous stress-strain curves of Cr-Mo steel, following the R6 approach, have been examined in ${ }^{15}$ where the influence of geometry, crack size and time on the TDFAD was found negligible. A simplified procedure for evaluating isochronous stress-strain curves has been proposed in ${ }^{13}$ (neglecting plasticity and assuming the elastic response of the entire weldment is equal to the PM's response) and applied to a $1 \mathrm{Cr} 0.5 \mathrm{Mo}$ steel weldment. A dependency of the TDFAD on time was shown in ${ }^{13}$, however, the deviation of the weldments TDFAC from the PM is curve was not demonstrated.

Since the TDFAD is being used to predict $\mathrm{CCl}$ it is expected that creep fracture would be the failure mode predicted. This is true for all cases examined for the $316 \mathrm{H}$ PM and weldments and the majority of cases for the P22 PM and weldment analyses using the lower bound $K_{c}^{\text {mat }}$, which leads to higher $K_{r}$ values. However, for the vast majority of cases failure by plastic collapse is predicted for the P22 PM and weldment analyses when the mean $K_{c}^{\text {mat }}$ values are employed, which is considered unrealistic. This is due to the strong time dependence of $\sigma_{0.2}^{c}$ causing a rapid increase of $L_{r}$ to 
values greater than $L_{r}^{\max }$. The time dependency of the rupture stress $\sigma_{r}$ is small in relation to $\sigma_{0.2}^{c}$, thus $L_{r}^{\text {max }}$ calculated from Eqn (8), indicating creep rupture, does not fall below that of Eqn (5), indicating plastic collapse.

There are considerable differences between the TDFADs for both steels. It has been demonstrated here and previously elsewhere (see e.g. ${ }^{8}$ ), that due to the insensitivity of the $316 \mathrm{H}$ steels TDFAC to time a single curve for a given time or even the R6 Option 1 curve may suffice. However, the significant time dependency of the P22 steel shown here demonstrates that this is not the case for this ferritic steel. This was also noted for the similar steel examined in ${ }^{37}$. An influence of tensile curve fitting on the accuracy of the results was noted in ${ }^{5}$. The Ramberg-Osgood material model widely employed to describe a materials tensile response is known to cause inaccuracies especially for high strain hardening austenitic steels ${ }^{38}$. In this work however such issues are negated by employing the materials experimentally measured tensile test data.

The $K_{c}^{\text {mat }}$ estimates obtained from using CCI and CCG data (see Eqn (21) and (22)) have been unsuccessful for the cases examined here, though they have provided satisfactory results elsewhere ${ }^{8,10}$. The best fit line from Eqn (24) has provided a reasonable fit to all the P22 $K_{c}^{\text {mat }} v s$. time data and to the short term $316 \mathrm{H}$ data, but can not describe the longer term $316 \mathrm{H}$ steel data. The apparent change in slope between the long term and short term $K_{c}^{\text {mat }} v s$. time data may indicate a change in material fracture behaviour, as suggested in ${ }^{31}$. However, within the extent of data scatter no firm conclusions can be made.

The influence of using the LB bound or mean $K_{c}^{\text {mat }}$ value has been examined here, and significant differences are obtained in both cases, including a change of predicted failure mode for the P22 steel. The influence of the reference stress solution on the $\mathrm{CCl}$ predictions has previously been examined in ${ }^{9}$. The plane stress reference stress is greater than the plane strain reference stress and therefore leads to higher degrees of conservatism. Using the plane stress reference stress solution with a LB $K_{c}^{\text {mat }}$ value will therefore lead to conservative predictions for all cases considered here.

Long term CCl and CCG tests are more representative of component operating conditions. The difference between the CCG rate and $K_{c}^{\text {mat }}$ trends for long and short term data signify that more long term tests are required to verify the TDFAD prediction method for use in high temperature components.

\section{Conclusions}

The creep toughness parameter, $K_{c}^{\text {mat }}$, for a crack extension of $0.2 \mathrm{~mm}$ and $0.5 \mathrm{~mm}$ has been determined for an austenitic $316 \mathrm{H}$ steel at $550{ }^{\circ} \mathrm{C}$ and ferritic P22 steel at $565{ }^{\circ} \mathrm{C}$ from creep crack growth (CCG) tests on the compact tension, $\mathrm{C}(\mathrm{T})$, specimen geometry. Both homogenous parent material (PM) and weldment specimen tests have been considered. $K_{c}^{\text {mat }}$ shows a relatively weak dependency on time for the P22 steel, however a clear decrease in $K_{c}^{\text {mat }}$ with time is observed for 
the $316 \mathrm{H}$ material, especially at long times. Significant data scatter has been observed in the $K_{c}^{\text {mat }}$ data for both materials, which has been quantified. For the P22 steel the influence of $K_{c}^{\text {mat }}$ on time had to be predicted using models since, due to the extent of data scatter within the relatively small data set, a sensible regression line fit could not be achieved. For a given time, the mean $K_{c}^{\text {mat }}$ values of the 316 weldment specimens are found to be a factor of 2 less than that of the PM specimens. Within the extent of data scatter, little difference in creep toughness behaviour is observed between the two material conditions for the P22 steel. Isochronous stressstrain curves and time dependent failure assessment diagrams (TDFAD) have been shown for a range of times for both the $316 \mathrm{H}$ and P22 PM steels. Due to the relatively low creep strain rates in the $316 \mathrm{H}$ steel at $550{ }^{\circ} \mathrm{C}$, these curves are relatively insensitive to time and little change is observed in the $316 \mathrm{H}$ materials $0.2 \%$ creep strength $\sigma_{0.2}^{c}$ for times less than $10,000 \mathrm{hrs}$. On the contrary the P22 curves rapidly deviate from their tensile curves (at $t=0 \mathrm{hrs}$ ) and $\sigma_{0.2}^{c}$ halves within the first hour of creep. A program has been developed to obtain explicit creep crack Initiation $(\mathrm{CCl})$ time predictions using the TDFAD method. $\mathrm{CCl}$ time predictions have been obtained for the CGG tests on the PM and weldment $\mathrm{C}(\mathrm{T})$ specimens and in addition for CCG data on PM and welded P22 pipe feature tests using the TDFAD derived from PM data. Reasonable predictions are generally obtained using the mean bound value of $K_{c}^{\text {mat }}$, though not always conservative assuming plane strain conditions. Conservative predictions are almost always obtained when LB $K_{c}^{\text {mat }}$ values are employed and may be ascertained by assuming plane stress conditions. Although considerable differences are observed in the form of the $K_{c}^{\text {mat }}$ data and TDFADs of both austenitic $316 \mathrm{H}$ steel at $550{ }^{\circ} \mathrm{C}$ and ferritic P22 steel at $565{ }^{\circ} \mathrm{C}$ reasonable and conservative $\mathrm{CCl}$ time predictions can be achieved for both materials following the TDFAD approach. It is however essential that the influence of time on the TDFAD is considered for the P22 steel. Further long term tests are recommended for the validation of the TDFAD method to predict the $\mathrm{CCl}$ times of in-service components.

\section{References}

1. Webster GA, Ainsworth RA (1994) High Temperature Component Life Assessment. 1st edn. Chapman and Hall, London.

2. ASTM (2007) E1457-07: Measurement of Creep Crack Growth Times in Metals. Annual Book of ASTM Standards. ASTM International, 1012-1035.

3. BEGL (2003) An Assessment Procedure for the High Temperature Response of Structures. British Energy Generation Ltd.

4. Lamb M (2001) A Review of Creep Toughness of Ferritic Steels. BNFL.

5. Dogan B, Petrovski B, Ceyhan U (2005) High Temperature Crack Initiation and Defect Assessment of Power Plant Steel Weldments. In: Shibli IA, Holdsworth SR, Merckling G, eds. Creep \& Fracture in High Temperature Components - Design and Life Assessment Issues, ECCC Creep Conference. PA: DEStech Publications, IMechE, London.

6. Fedeli G, Gampe, U., Prunier, V., Nikbin, K. M., Andersson, H., Patiraj, B. and Shibli, I. A. (1998) HIDA Activity on 2 $\frac{1}{4} 4 \mathrm{Cr} 1 \mathrm{Mo}$ Steel. Materials at High Temperature. 15: 27-35.

7. Kutz M (2002) Handbook of materials selection John Wiley and Sons, New York ; Chichester 
8. Ainsworth RA, Hooton, D. G. and Green, D. (1999) Failure Assessment Diagrams for High Temperature Defect Assessment. Engineering Fracture Mechanics. 62: 95-109.

9. Davies CM, O'Dowd NP, Dean DW, Nikbin KM, Ainsworth RA (2003) Failure Assessment Diagram Analysis of Creep Crack Initiation in $316 \mathrm{H}$ Stainless Steel. International Journal of Pressure Vessels and Piping. 80: 541-551.

10. Xuan FZ, Tu ST, Wang ZD, Gong JM (2005) On the Creep Fracture Toughness of 21/4Cr1Mo Steel. Key Engineering Materials. 297-300: 14641469.

11. Mueller F, Scholz A, Berger C (2007) Comparison of Different Approaches for the Estimation of Creep Crack Initiation. Engineering Failure Analaysis. 14: 1574-1585.

12. Dogan B, Ceyhan U, Petrovski B (2007) High Temperature Crack Initiation and Defect Assessment of P22 Steel Weldments using Time Dependent Failure Assessment Method. Engineering Fracture Mechanics. 74: 839-852.

13. Ma CW, Xuan F, Wang ZD, Tu ST (2004) Isochronous Stress Strain Curves of Low Alloy Steel Cross Weld Specimen In High Temperature. Acta Metallurgica Sinica (English Letters). 17: 612-617.

14. Dogan B, Ceyhan U, Nikbin KM, Petrovski B, Dean DW (2005) European Code of Practice for Creep Crack Initiation and Growth Testing of Industrial Specimens. Submitted for Publication.

15. Xuan F-Z, Tu S-T, Wang Z (2006) A Modified Time-Dependent Failure Assessment Diagram for Cracks in Mismatched Welds at High Temperatures. 29: 157-166.

16. Davies CM, Dean DW, Nikbin KM, O'Dowd NP (2007) Interpretation of Creep Crack Initiation and Growth Data for Weldments. Engineering Fracture Mechanics, 882-897.

17. BEGL (2001) Assessment of the Integrity of Structures Containing Defects. British Energy Generation Ltd.

18. British Standard (1999) BS 7910: Guide on Methods for Assessing the Acceptability of Flaws in Metallic Structures. BSI, London.

19. Ainsworth RA, Budden PJ (1990) Crack Tip Fields under Non-Steady Creep Conditions-I. Estimates of the Amplitude of the Fields. Fatigue \& Fracture of Engineering Materials \& Structures. 13: 263-276.

20. RCC-MR (1985) Design and Construction Rules for Mechanical Components of FBR Nuclear Island. AFCEN, Paris.

21. Davies CM, Kourmpetis M, O'Dowd NP, Nikbin KM (2006) Experimental Evaluation of the $J$ or $C^{*}$ Parameter for a Range of Cracked Geometries. Journal of ASTM International.

22. Ainsworth RA (1993) The Use of a Failure Assessment Diagram for Initiation and Propagation of Defects at High Temperature. Fatigue Fracture of Engineering Materials and Structures. 16: 1091-1108.

23. Nikbin KM, Smith, D. J. and Webster, G. A. (1983) Influence of Creep Ductility and State of Stress on Creep Crack Growth. Advances in Life Prediction Methods at Elevated Temperatures. 249-258.

24. Nikbin KM, Smith, D.J., Webster, G.A. (1984) Prediction of Creep Crack Growth from Uniaxial Creep Data. Proceedings of the Royal Society. A 396: 183-197.

25. Austin TSP, Webster GA (1992) Prediction of Creep Crack Growth Incubation Periods. Fatigue and Fracture of Engineering Materials and Structures. 15: 1081-1090.

26. Célard N (2000) Determination of a Unified Defect Assessment Procedure for High Temperature Applications. Department of Mechanical Engineering. Imperial College London, London. 
27. Dean DW, Gladwin DN (2007) Creep Crack Growth Behaviour of Type 316H Steels and Proposed Modifications to Standard Testing and Analysis Methods. The International Journal of Pressure Vessels and Piping. 84: 378-395.

28. Bettinson AD (2002) The Influence of Constraint on the Creep Crack Growth of $316 \mathrm{H}$ Stainless Steel. Department of Mechanical Engineering. Imperial College London, London.

29. Davies CM, Mueller F, Nikbin KM, O'Dowd NP, Webster GA (2006) Analysis of Creep Crack Initiation and Growth in Different Geometries for $316 \mathrm{H}$ and Carbon Manganese Steels. Journal of ASTM International.

30. Davies CM, Dean DW, Yatomi M, Nikbin KM (2008) The Influence of Test Duration and Geometry on the Creep Crack Initiation and Growth Behaviour of $316 \mathrm{H}$ Steel. to appear in Materials Science and Engineering A, Creep 2008 Special Issue.

31. Dean DW, Gladwin DN (2001) Characterisation of Creep Crack Growth Behaviour in Type $316 \mathrm{H}$ Steel using both $\mathrm{C}^{*}$ and Creep Toughness Parameters. In: Parker DJ, ed. Proceedings of the $9^{\text {th }}$ International Conference on Creep and Fracture of Engineering Materials and Structures, Swansea, 751-761.

32. Dean DW, O'Donnell M.P. (2001) Alternative Approaches in the R5 Procedures for Predicting Initiation and the Early Stages of Creep Crack Growth. Creep and Fatigue at Elevated Temperatures, Tsukuba, Japan, 315319.

33. Dean DW, Hooton DG (2003) A Review of Creep Toughness Data for Austenitic Type 316 Steels. British Energy Generation Ltd.

34. Wasmer K, Davies, C.M., Nikbin K.M., O'Dowd, N.P., Webster, G.A. (2003) A Study of Creep Crack Initiation and Growth in Welded P22 Steel Pipes. 2nd International Conference Integrity of High Temperature Welds. IOM Communications Ltd, London, 413-423.

35. Song T-K, Kim Y-J, Kim J-S, Jin T-E (2007) Mismatch limit loads and approximate $\mathrm{J}$ estimates for tensile plates with constant-depth surface cracks in the center of welds. International Journal of Fracture. 148: 343-360.

36. Dogan B, Petrovski B (2001) Creep crack growth of high temperature weldments. International Journal of Pressure Vessels and Piping. 78: 795-805.

37. Xuan F, Shandong T, Zhengsong W (2004) TDFAD Approach to High Temperature Defect Assessment and its Engineering Application. Chinease Journal of Mechanical Engineering. 17: 537-542.

38. Gardner L, Ashraf M (2006) Structural Design for Non-linear Metallic Materials. Engineering Structures. 28: 926-934. 


\section{Tables}

Table 1: Material properties for homogeneous parent material $316 \mathrm{H}$ stainless steel at $550{ }^{\circ} \mathrm{C}$ and P22 steel at $565^{\circ} \mathrm{C}$

\begin{tabular}{|l|c|c|}
\cline { 2 - 3 } \multicolumn{1}{c|}{} & $\mathbf{3 1 6 H}$ & $\mathbf{P 2 2}$ (PM) \\
\hline$A\left(\mathrm{MPa}^{1 / n} \mathrm{~h}^{-1}\right)$ & $1.47 \times 10^{-34}$ & $3.21 \times 10^{-27}$ \\
\hline$n$ & 11.58 & 10.68 \\
\hline$n_{p}$ & 7.45 & 2.47 \\
\hline$A_{p}\left(\mathrm{MPa}^{-n_{p}} t^{-p}\right)$ & $2.60 \times 10^{-23}$ & $1.0 \times 10^{-8}$ \\
\hline$p$ & 0.746 & 0.3 \\
\hline$E(\mathrm{MPa})$ & 140,000 & 140,135 \\
\hline$\sigma_{0.2}(\mathrm{MPa})$ & 170 & 284 \\
\hline$\sigma_{U T S}(\mathrm{MPa})$ & 442 & 365 \\
\hline$B_{r}\left(\mathrm{MPa}{ }^{v_{r}} \mathrm{~h}\right)$ & $5.27 \times 10^{31}$ & $1.43 \times 10^{22}$ \\
\hline$v_{r}$ & 11.3 & 9.11 \\
\hline$\sigma_{f l o w}(\mathrm{MPa})$ & 306 & 327 \\
\hline$\varepsilon_{f}(\%)(\mathrm{Eng})$ & 37 & 27 \\
\hline$\varepsilon_{f}^{c}(\%)(\mathrm{Axial})$ & 8 & 31 \\
\hline$\varepsilon_{f}^{c}(\%)(\mathrm{ROA})$ & 21 & 65 \\
\hline
\end{tabular}


Table 2: Regression fit constants to CCG rate vs. $C^{*}$ data (Eqn (19)) from long term (LT) and short term (ST) tests on 316H and tests on P22 steel.

\begin{tabular}{|l|c|c|c|}
\cline { 2 - 4 } \multicolumn{1}{c|}{} & $\mathbf{3 1 6 H} \mathbf{( L T )}$ & $\mathbf{3 1 6 H} \mathbf{( S T )}$ & P22 \\
\hline$D$ Mean & 9.25 & 3.45 & 4.52 \\
\hline$D$ UB & 16.91 & 8.26 & 16.87 \\
\hline$D$ LB & 5.06 & 1.44 & 1.21 \\
\hline$\phi$ & 0.73 & 0.75 & 0.75 \\
\hline
\end{tabular}


Table 3: Regression fit constants to $\mathrm{CCl}$ time vs. $C^{*}$ data (Eqn (20)) from tests on homogenous parent material $316 \mathrm{H}$ and $\mathrm{P} 22$ steel for crack extensions, $\Delta a$, of 0.2 and $0.5 \mathrm{~mm}$.

\begin{tabular}{|l|c|c|c|c|}
\cline { 2 - 5 } \multicolumn{1}{c|}{} & \multicolumn{2}{c|}{$316 \mathrm{H}$} & \multicolumn{2}{c|}{ P22 } \\
\hline$\Delta a(\mathrm{~mm})$ & 0.2 & 0.5 & 0.2 & 0.5 \\
\hline$D_{i}$ Mean & 0.7 & 3.9 & $9.3 \times 10^{-4}$ & 22.1 \\
\hline$D_{i}$ UB & 5.0 & 17.9 & $4.0 \times 10^{-3}$ & 4.5 \\
\hline$D_{i}$ LB & 0.1 & 0.8 & $2.2 \times 10^{-4}$ & 0.93 \\
\hline$\phi_{i}$ & 0.55 & 0.47 & 1.1 & 0.44 \\
\hline
\end{tabular}


Table 4: Mean, upper bound (UB) and lower bound (LB) regression fit constants to $K_{c}^{\text {mat }}$ vs. time data (Eqn (25)) of homogeneous parent material (PM) and weldment

$316 \mathrm{H}$ and P22 PM specimens.

\begin{tabular}{|l|c|c|c|c|c|c|}
\cline { 2 - 7 } \multicolumn{1}{c|}{} & \multicolumn{2}{c|}{ 316H } & \multicolumn{2}{c|}{ 316H } & \multicolumn{2}{c|}{ P22 } \\
\hline \multicolumn{2}{c|}{ PM } & \multicolumn{2}{c|}{ Weldment } & \multicolumn{2}{c|}{ PM } \\
\hline$H$ (mm) & 0.2 & 0.5 & 0.2 & 0.5 & 0.2 & 0.5 \\
\hline$H$ Mean & 242.4 & 224.5 & 117.8 & 173.0 & 29.8 & 73.3 \\
\hline$H$ LB & 449.7 & 611.5 & 211.8 & 289.0 & 51.5 & 136.8 \\
\hline$j$ & 130.6 & 224.5 & 65.5 & 103.5 & 17.3 & 39.3 \\
\hline
\end{tabular}


Table 5: Mean, upper bound (UB) and lower bound (LB) constants for the $K_{c}^{\text {mat }}$ v.s. time relationship of Eqn (25) for homogenous parent material (PM) specimens of $316 \mathrm{H}$ and of P22 steel, and weldment specimens of P22 steel assuming $j=1 /(2 n)$

\begin{tabular}{|c|c|c|c|c|c|c|}
\cline { 2 - 7 } \multicolumn{1}{c|}{} & \multicolumn{2}{c|}{$316 \mathrm{H}$} & \multicolumn{4}{c|}{ P22 } \\
\cline { 2 - 7 } \multicolumn{1}{c|}{} & \multicolumn{2}{c|}{$\mathrm{PM}$} & \multicolumn{2}{c|}{ PM } & \multicolumn{2}{c|}{ Weldment } \\
\hline$\Delta a(\mathrm{~mm})$ & 0.2 & 0.5 & 0.2 & 0.5 & 0.2 & 0.5 \\
\hline$H$ Mean & 119.8 & 135.1 & 51.35 & 71.96 & 47.2 & 62.1 \\
\hline$H$ UB & 222.2 & 223.0 & 88.68 & 134.3 & 69.5 & 88.3 \\
\hline$H$ LB & 64.5 & 81.9 & 29.73 & 38.56 & 32.0 & 43.7 \\
\hline$j=1 /(2 n)$ & \multicolumn{2}{|c|}{0.043} & \multicolumn{2}{c|}{0.047} & \multicolumn{2}{c|}{0.047} \\
\hline
\end{tabular}




\section{Figures}

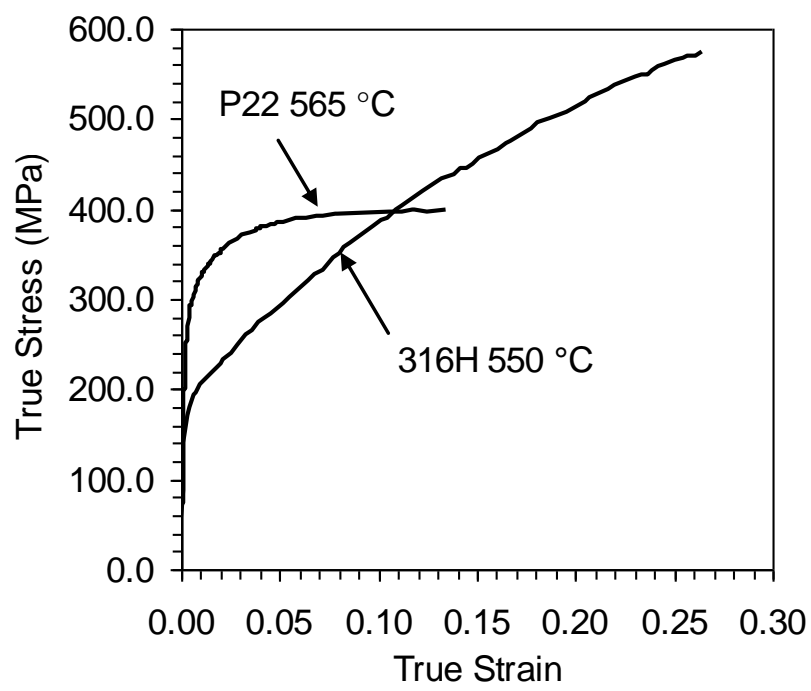

Figure 1: Comparison of the high temperature tensile behaviour of $316 \mathrm{H}$ stainless steel at $550{ }^{\circ} \mathrm{C}$ and ferritic P22 steel at $565^{\circ} \mathrm{C}$. 

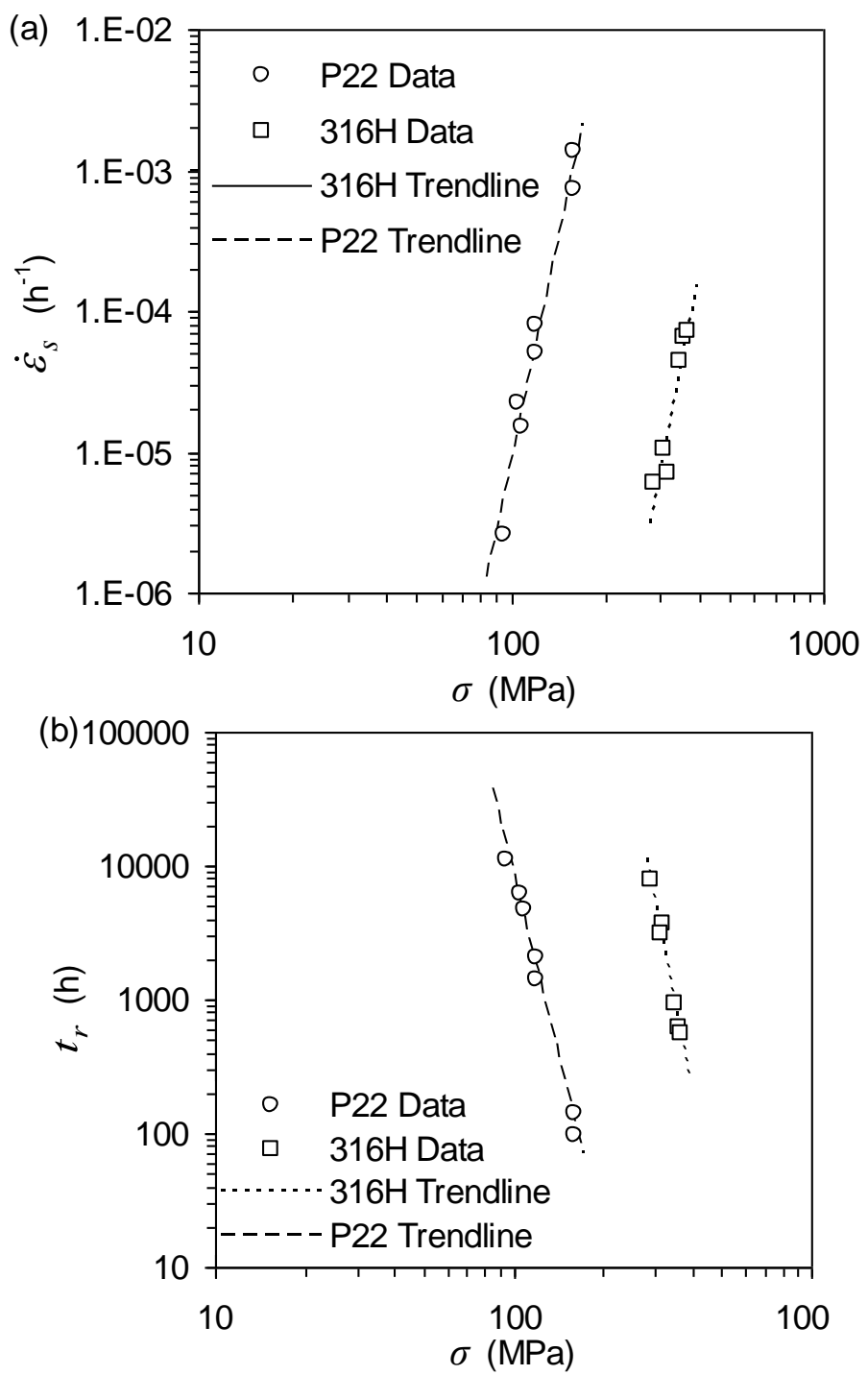

Figure 2: Comparison of (a) secondary creep strain rates and (b) creep rupture time with stress for $316 \mathrm{H}$ at $550{ }^{\circ} \mathrm{C}$ and P22 at $565^{\circ} \mathrm{C}$. 


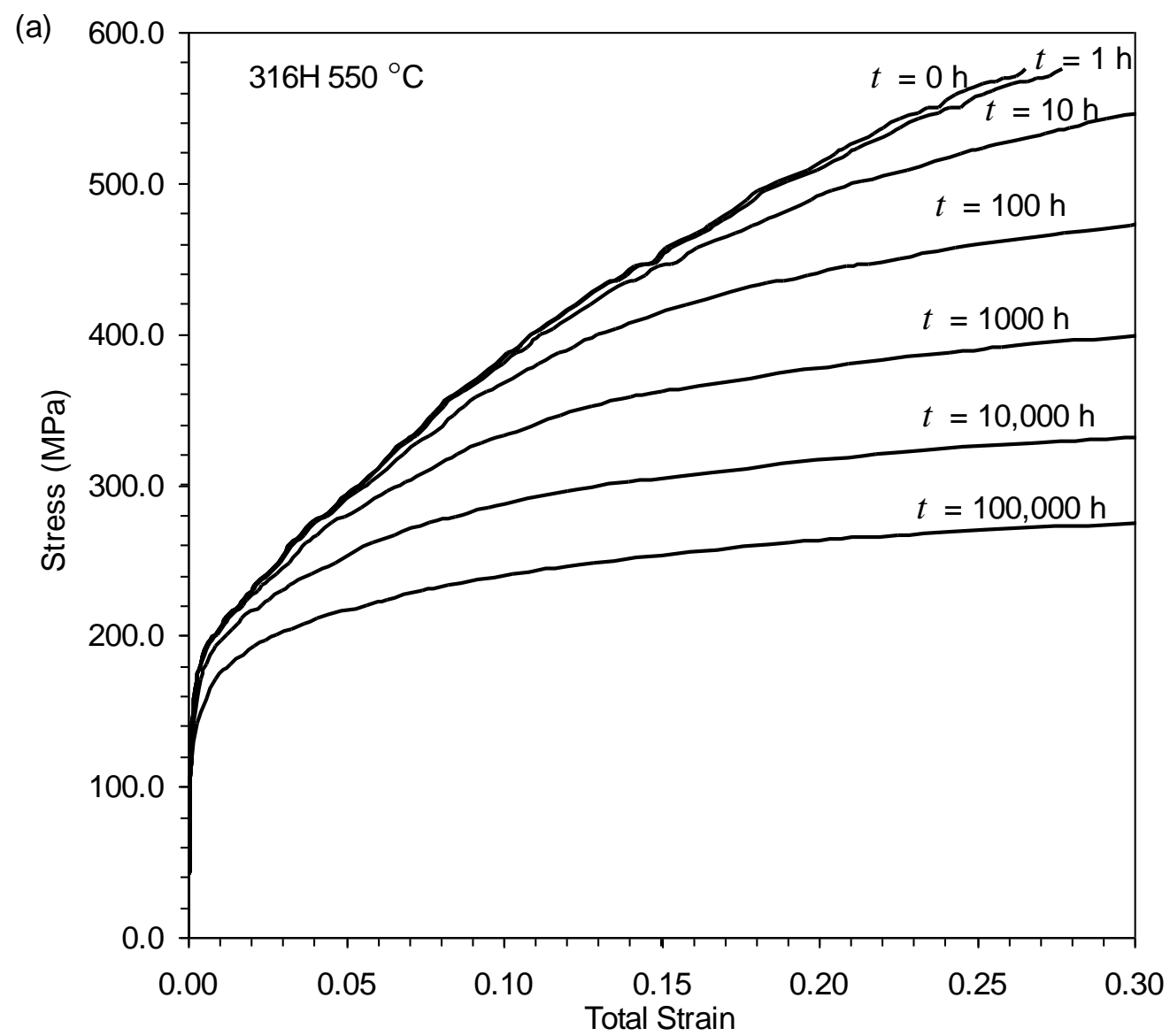




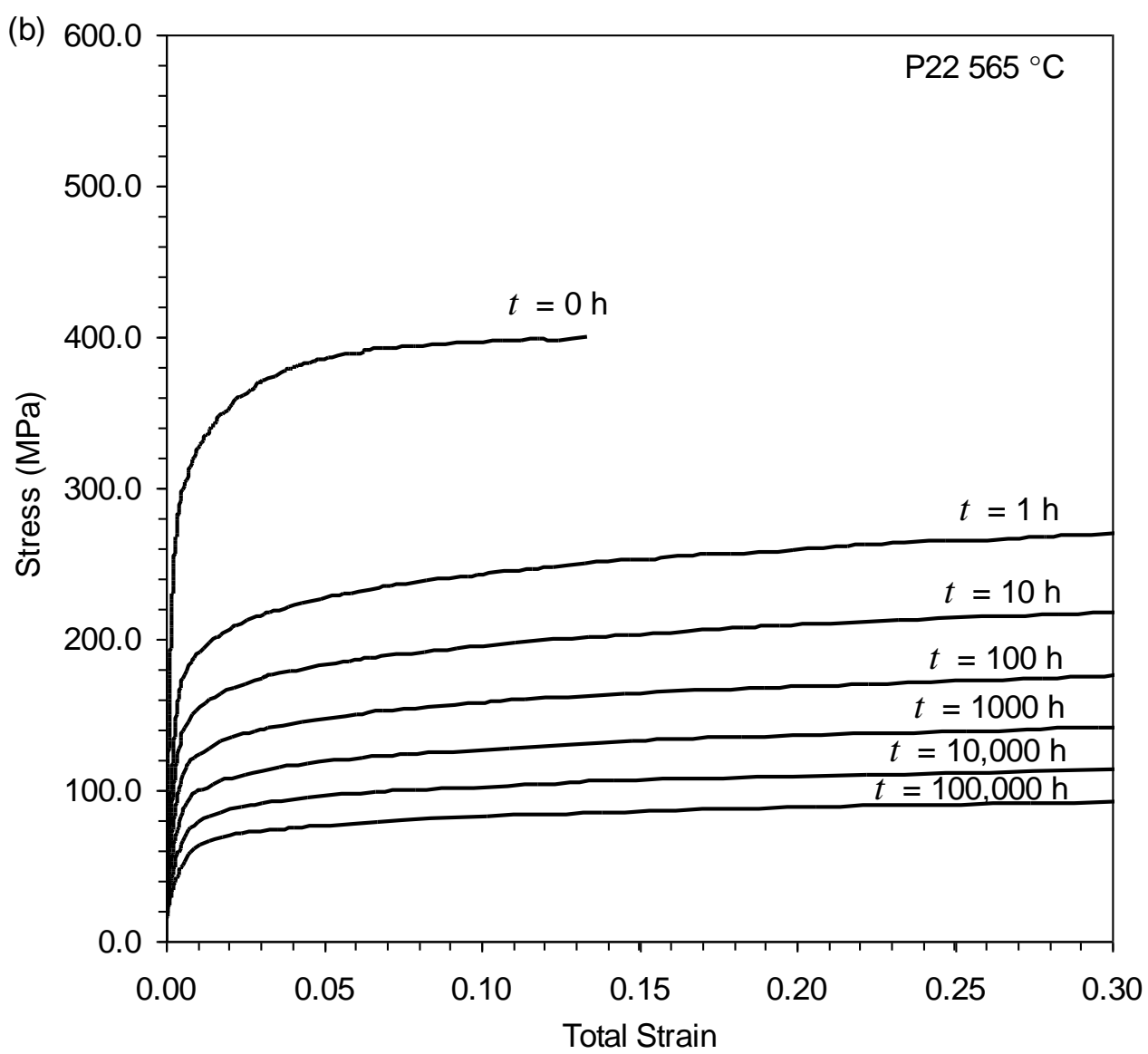

Figure 3: The isochronous stress strain curves at a range of times for (a) $316 \mathrm{H}$ stainless steel at $550{ }^{\circ} \mathrm{C}$ and (b) ferritic P22 steel at $565^{\circ} \mathrm{C}$. 


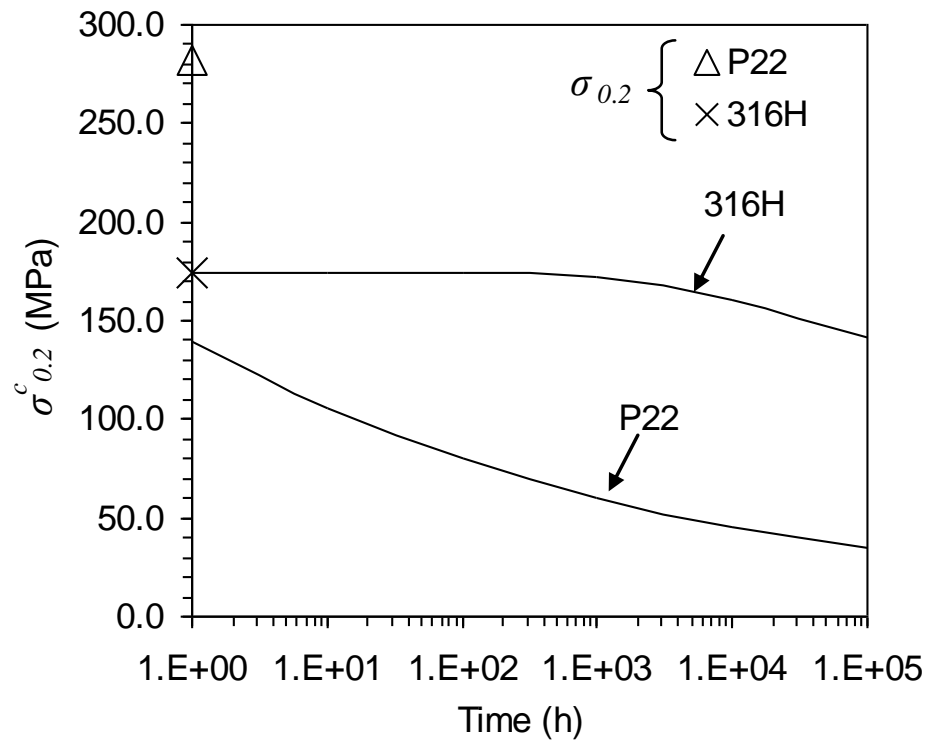

Figure 4: Evolution of the $0.2 \%$ creep strength, $\sigma_{0.2}^{c}$, with time of the $316 \mathrm{H}$ stainless steel at $550^{\circ} \mathrm{C}$ and P22 steel at $565^{\circ} \mathrm{C}$. 

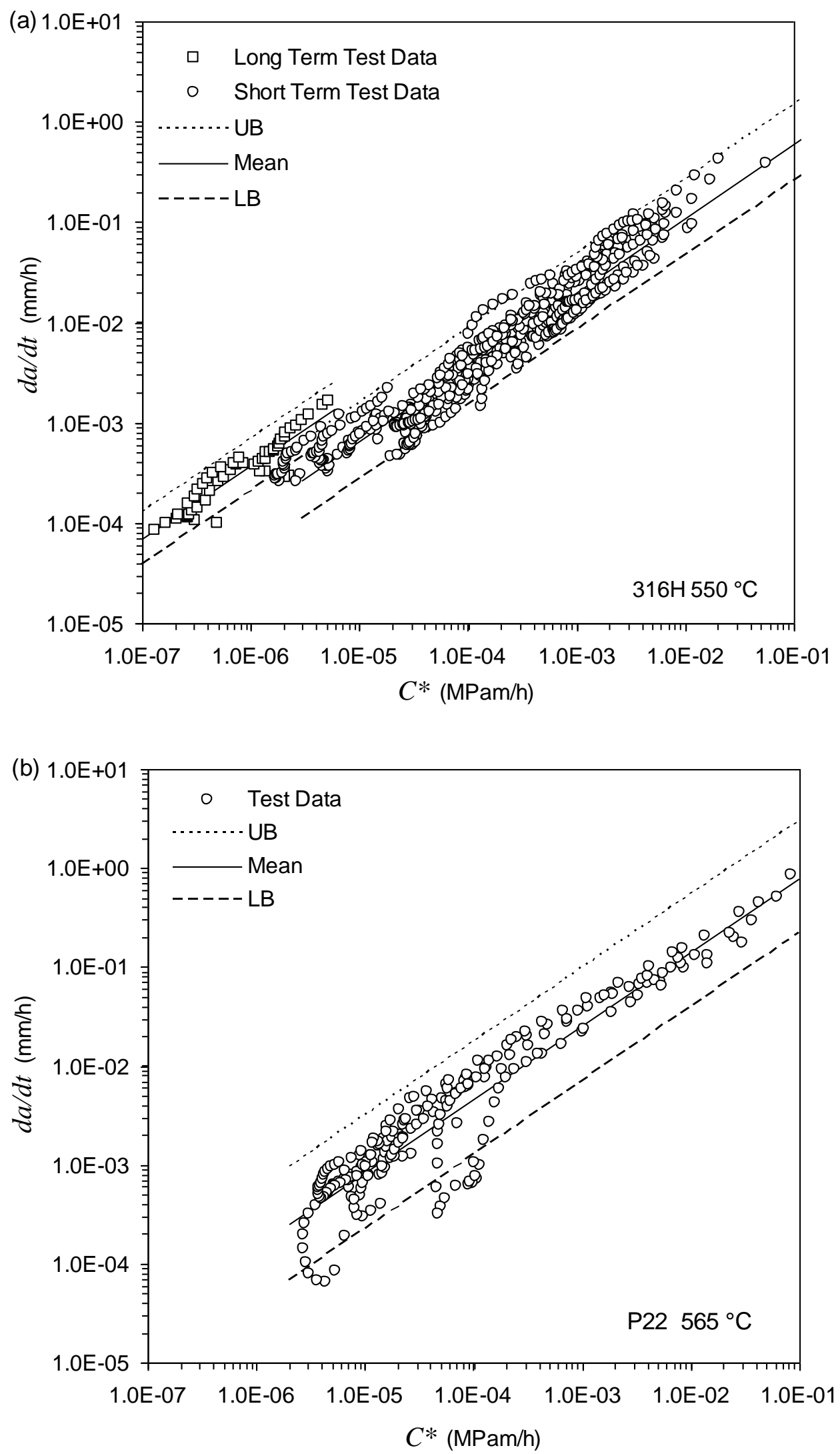

Figure 5: CCG rate correlations with the $C^{*}$ parameter for (a) $316 \mathrm{H}$ stainless steel at $550{ }^{\circ} \mathrm{C}$ and (b) P22 steel at $565^{\circ} \mathrm{C}$ including data bounds. 


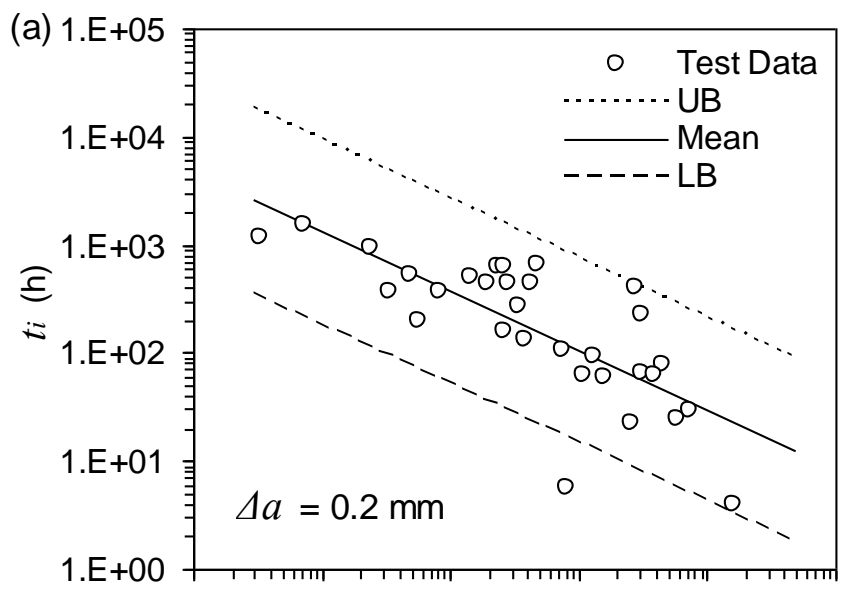

1.0E-07 1.0E-06 1.0E-05 1.0E-04 1.0E-03 1.0E-02

$C^{*}(\mathrm{MPam} / \mathrm{h})$

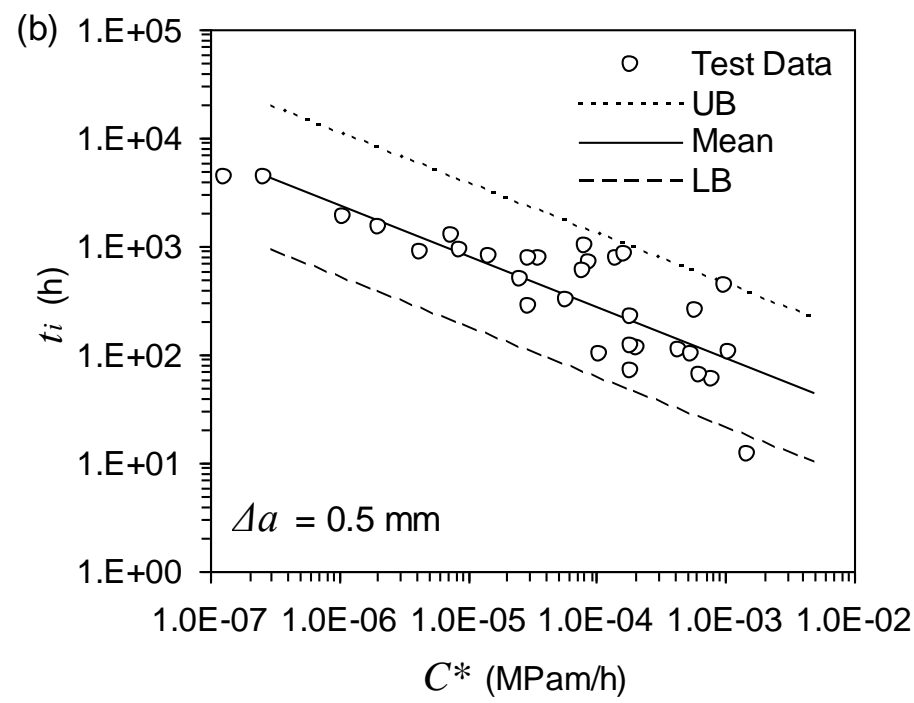

Figure 6: $\mathrm{CCl}$ time correlations with the $C^{*}$ parameter at (a) $\Delta a=0.2 \mathrm{~mm}$ and (b) $\Delta a=0.5 \mathrm{~mm}$ for $316 \mathrm{H}$ stainless steel at $550{ }^{\circ} \mathrm{C}$, including data bounds. 

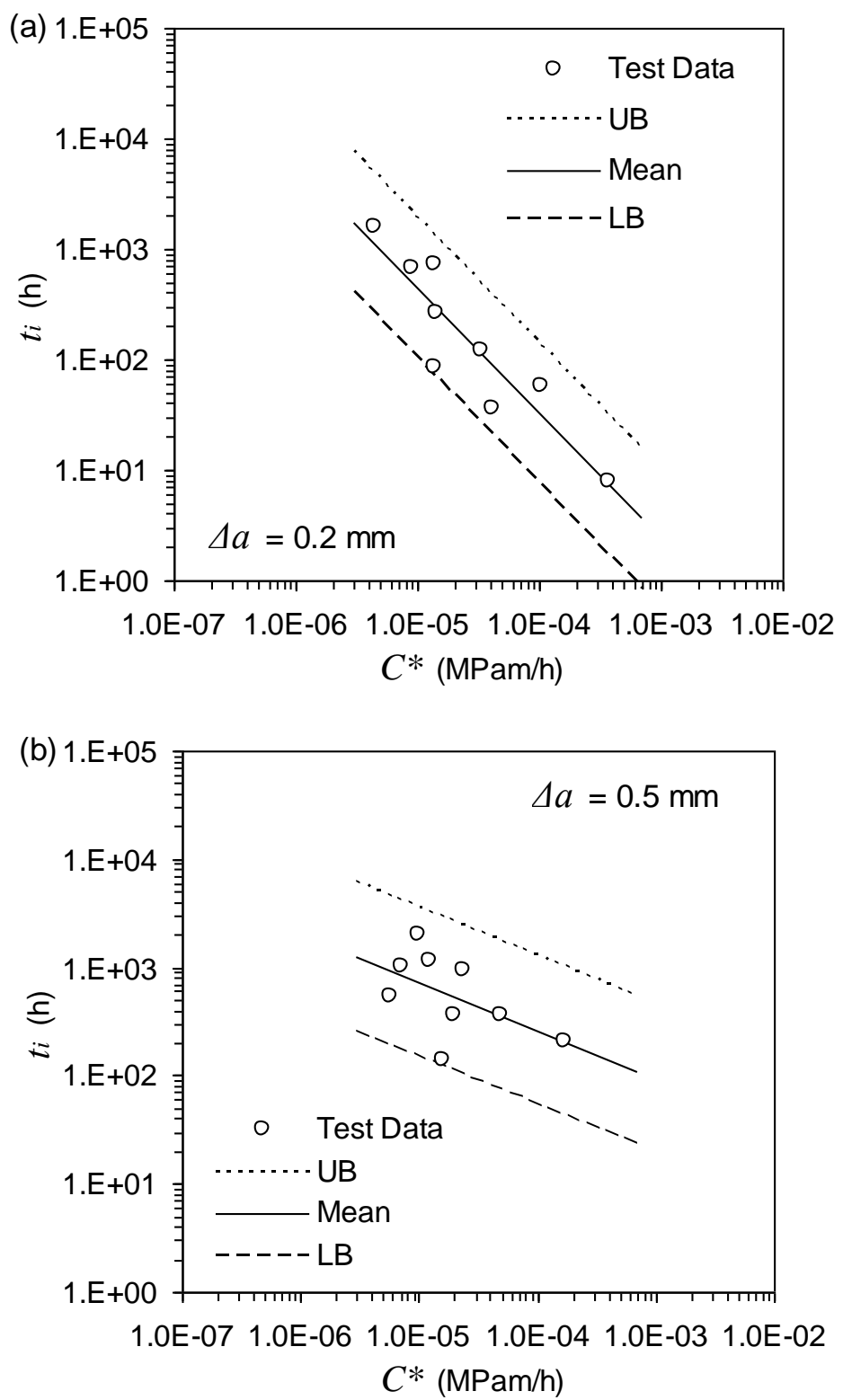

Figure 7: $\mathrm{CCl}$ time correlation with the $C^{*}$ parameter at (a) $\Delta a=0.2 \mathrm{~mm}$ and (b) $\Delta a=0.5 \mathrm{~mm}$ for $\mathrm{P} 22$ steel at $565^{\circ} \mathrm{C}$, including data bounds. 

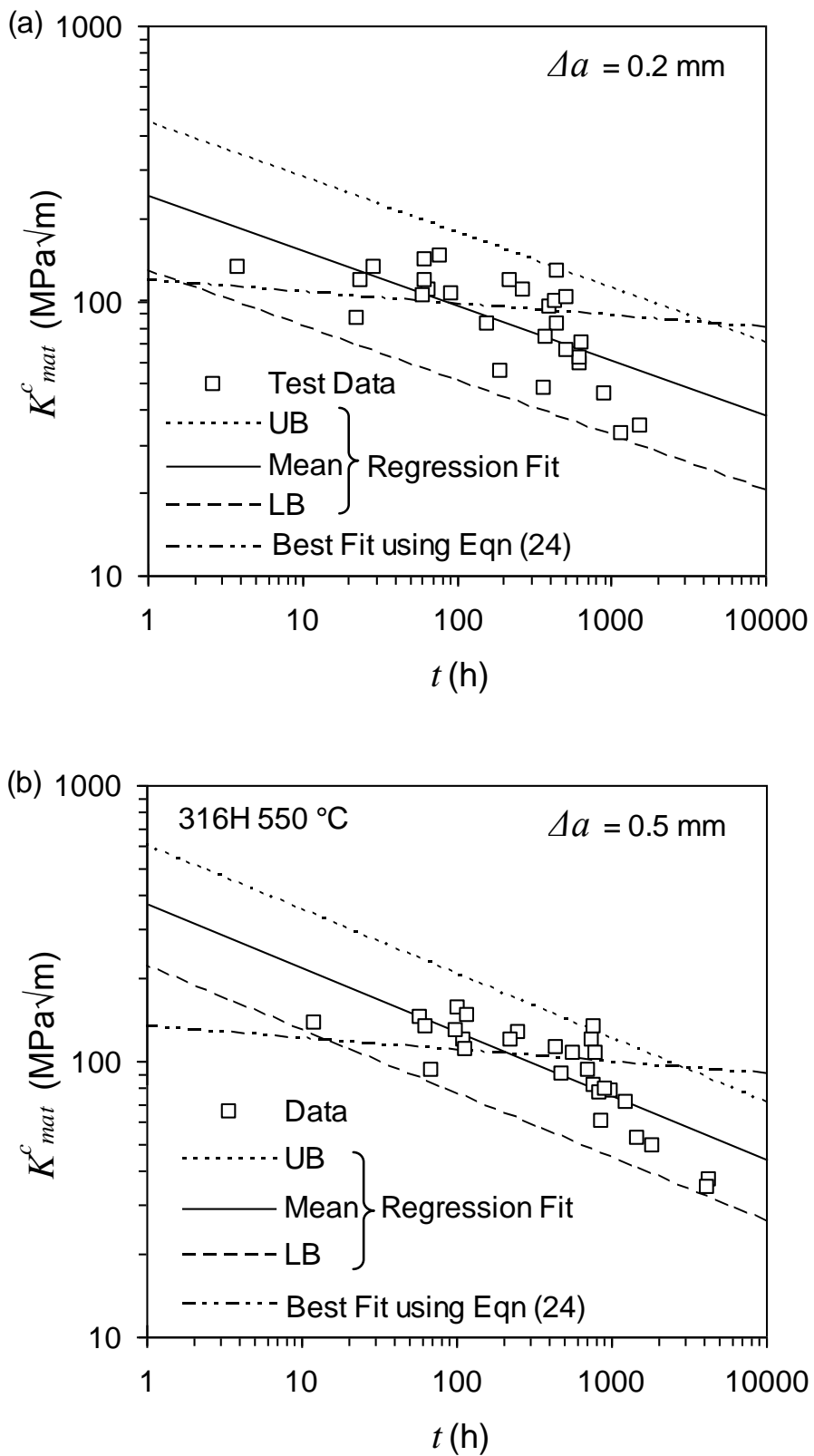

Figure 8: Creep toughness vs. time data for $316 \mathrm{H}$ stainless steel at $550{ }^{\circ} \mathrm{C}$ at (a) $\Delta a=0.2 \mathrm{~mm}$ and (b) $\Delta a=0.5 \mathrm{~mm}$, including mean and upper/lower bound regression fits and the best fit using Eqn (24). 

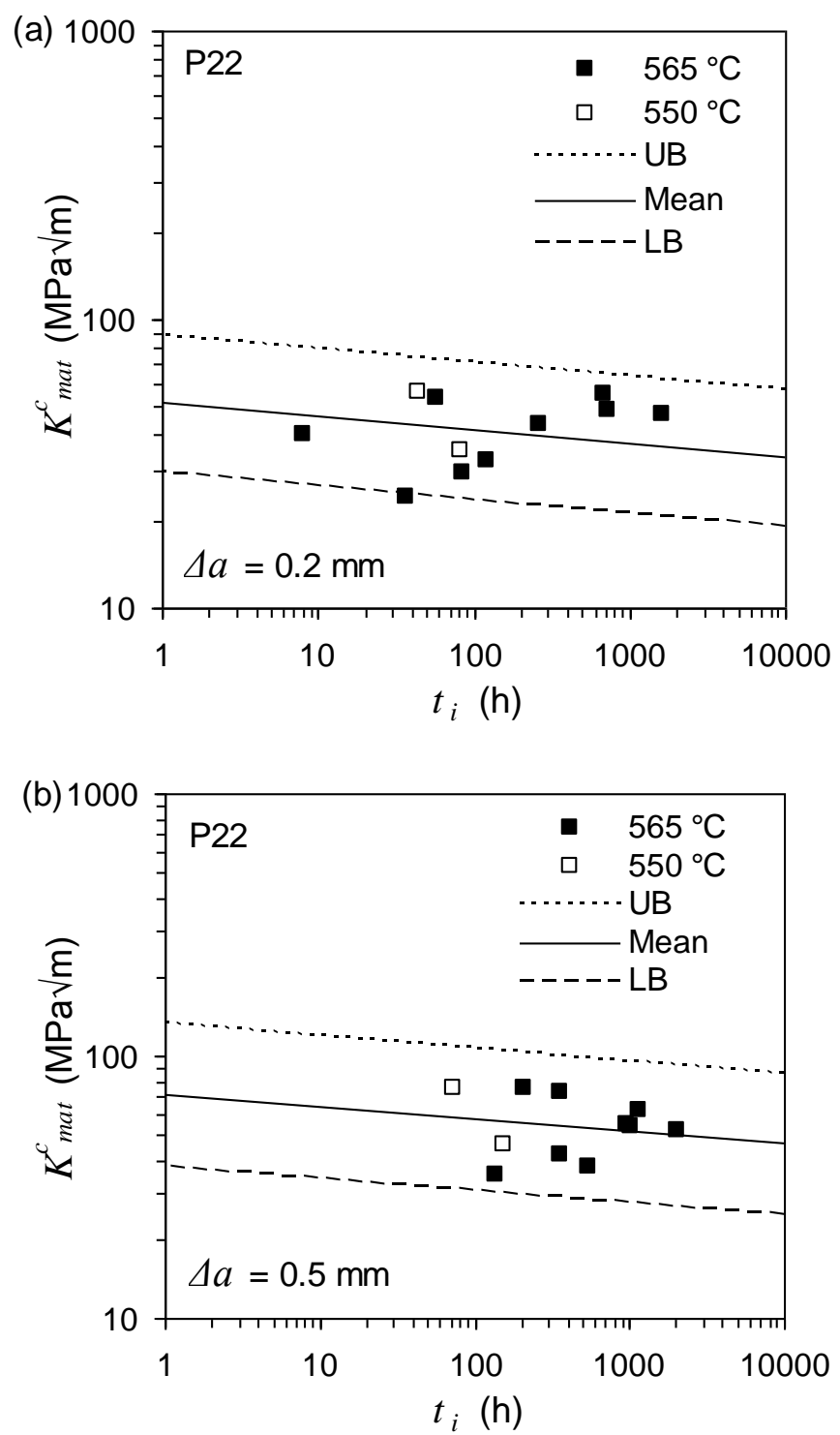

Figure 9: Creep toughness vs. time data for ferritic P22 steel PM at (a) $0.2 \mathrm{~mm}$ (b) $0.5 \mathrm{~mm}$, including mean, upper/lower bound fitted lines. 

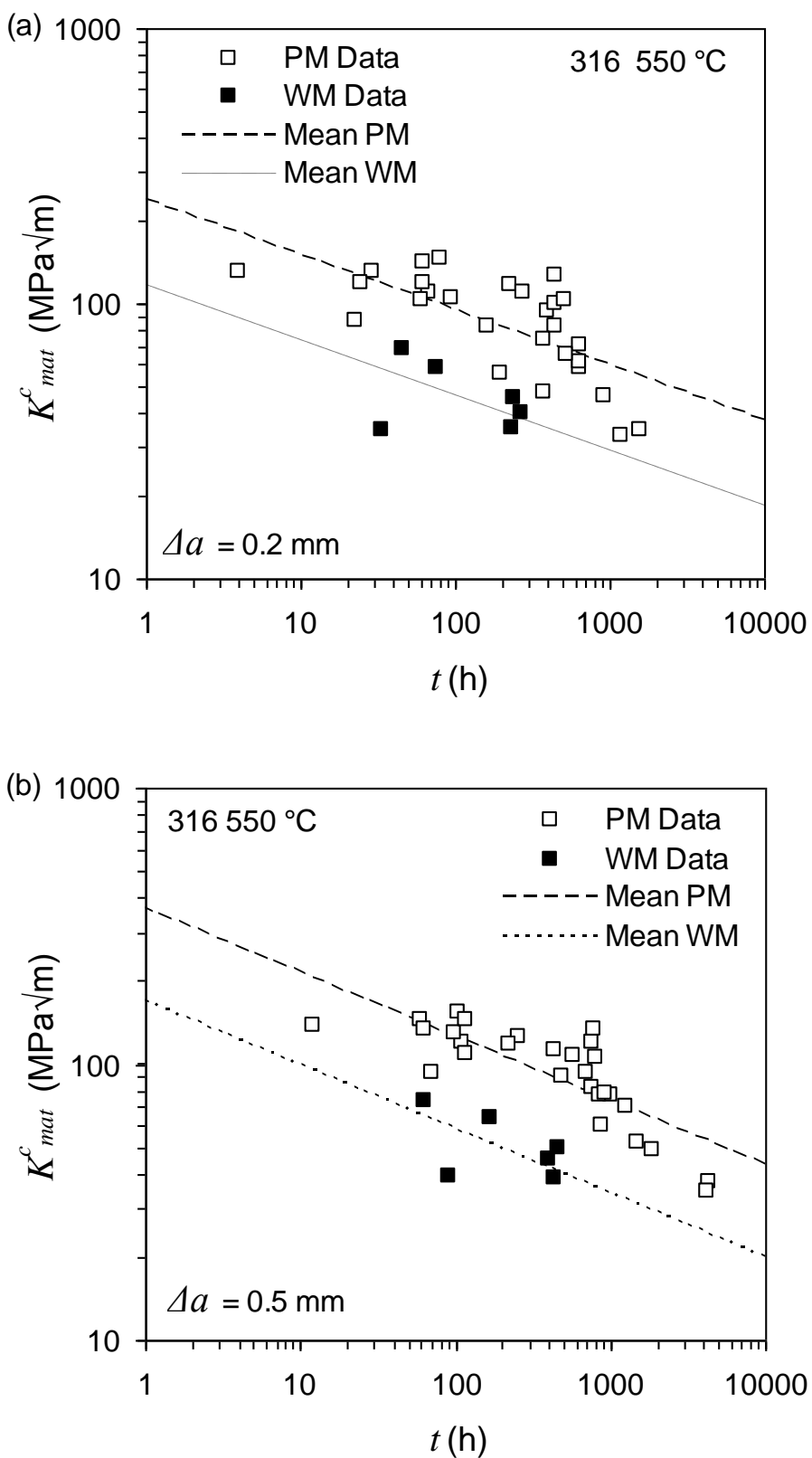

Figure 10: Comparison of the creep toughness vs. time data for $316 \mathrm{H}$ stainless steel at (a) $0.2 \mathrm{~mm}$ (b) $0.5 \mathrm{~mm}$, for homogenous PM and weldment $\mathrm{C}(\mathrm{T})$ specimens. 

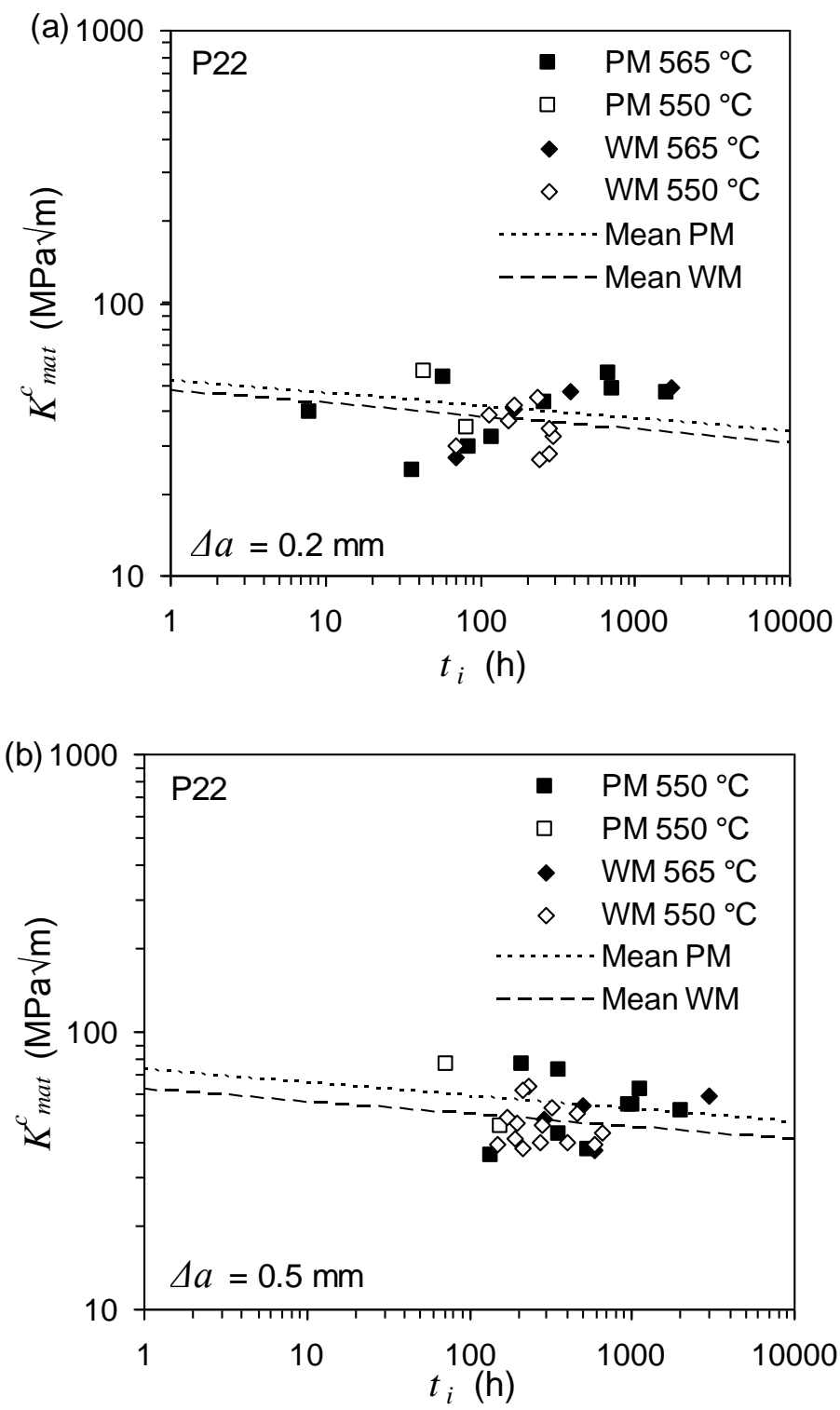

Figure 11: Comparison of the creep toughness vs. time data for P22 steel at $565{ }^{\circ} \mathrm{C}$ at (a) $0.2 \mathrm{~mm}$ (b) $0.5 \mathrm{~mm}$, for homogenous $\mathrm{PM}$ and weldment $\mathrm{C}(\mathrm{T})$ specimens. 

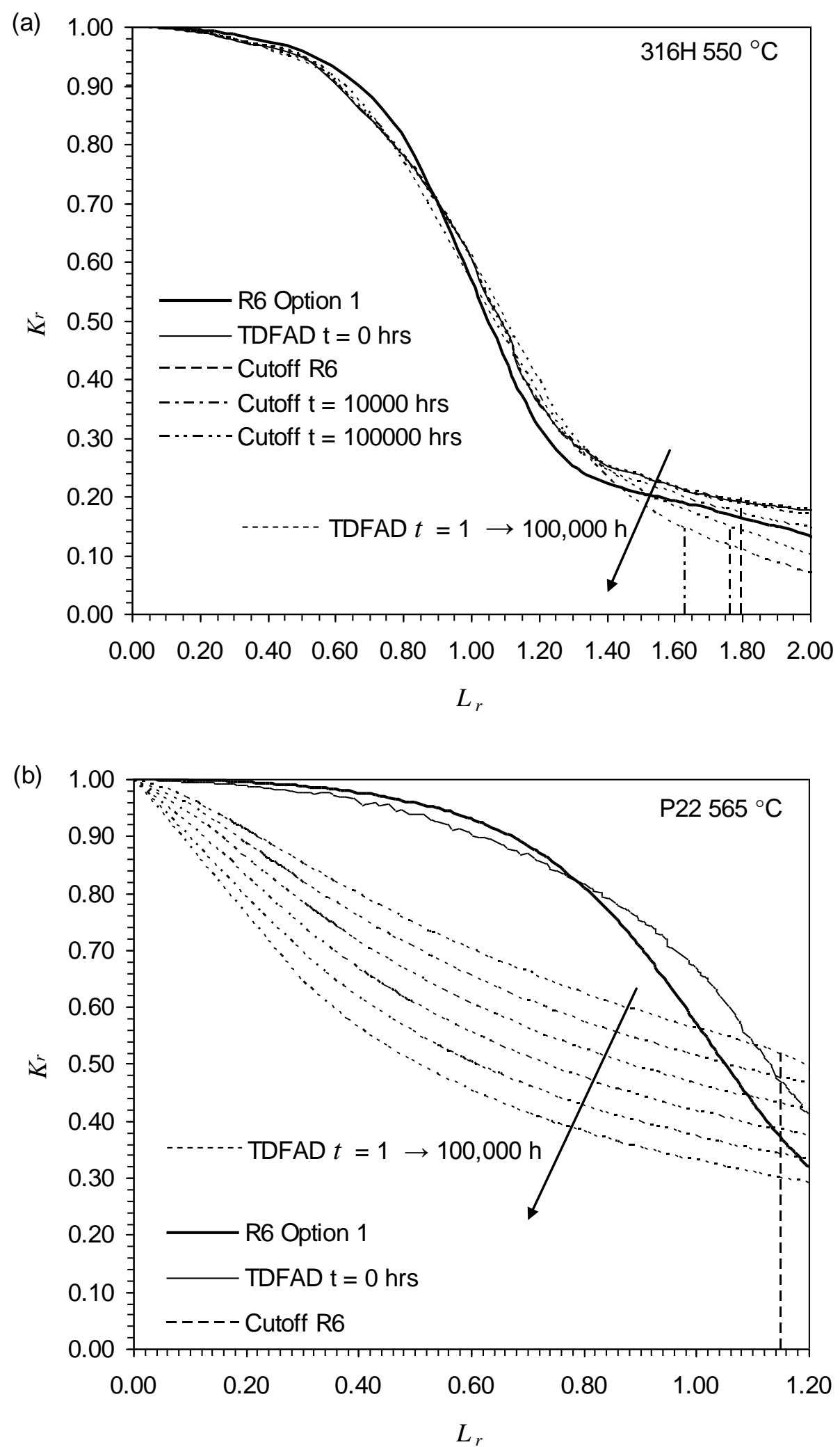

Figure 12: Comparison of the TDFADs at various times with the R6 Option1 curve for homogenous PM (a) $316 \mathrm{H}$ stainless steel at $550{ }^{\circ} \mathrm{C}$ and (b) P22 steel at $565^{\circ} \mathrm{C}$. 


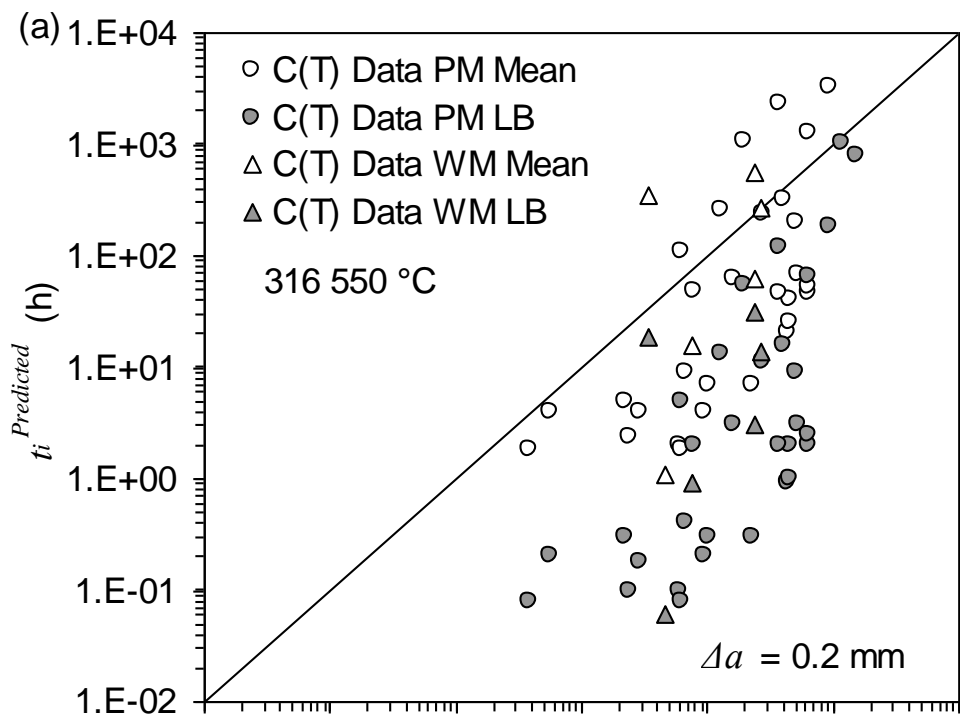

1.E-02 1.E-01 1.E+00 1.E+01 1.E+02 1.E+03 1.E+04

$$
t_{i}^{E x p}(\mathrm{~h})
$$

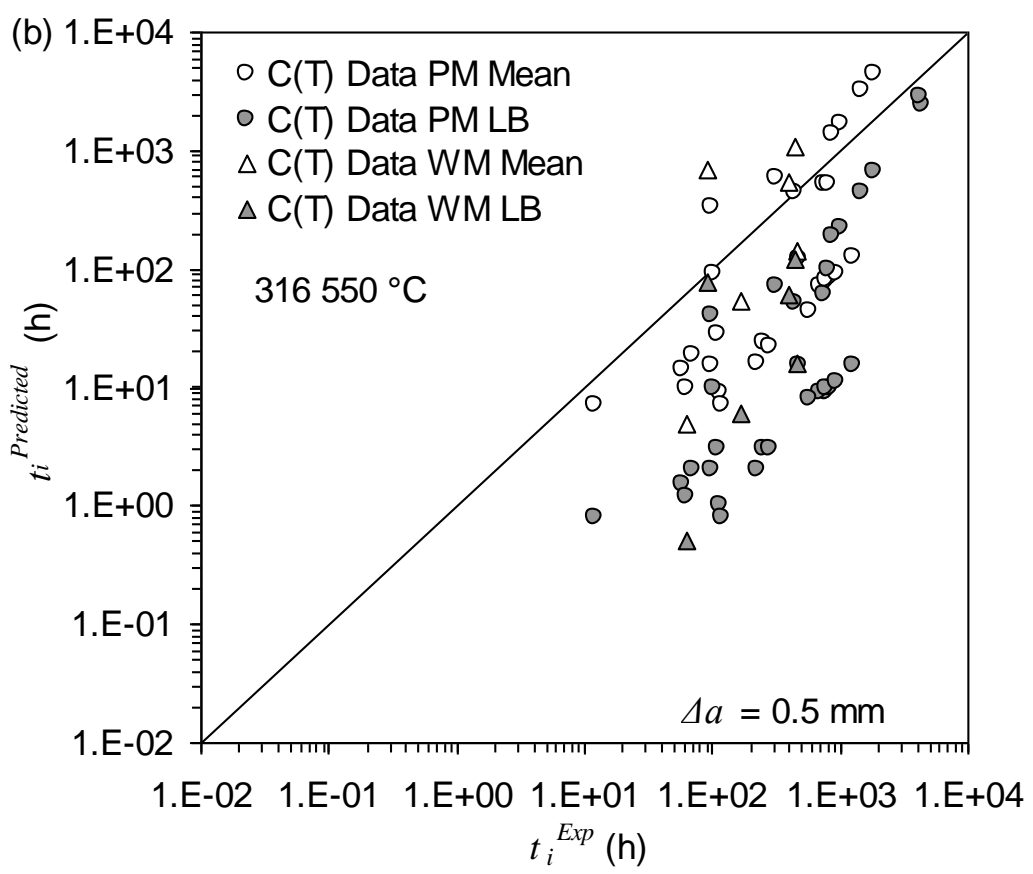

Figure 13: Comparison of the predicted and experimentally determined $\mathrm{CCl}$ times from tests on homogenous PM and weldment C(T) specimens of 316 steel at $550{ }^{\circ} \mathrm{C}$ for (a) $0.2 \mathrm{~mm}$ and (b) $0.5 \mathrm{~mm}$, using mean and lower bound $K_{c}^{\text {mat }}$ values. 


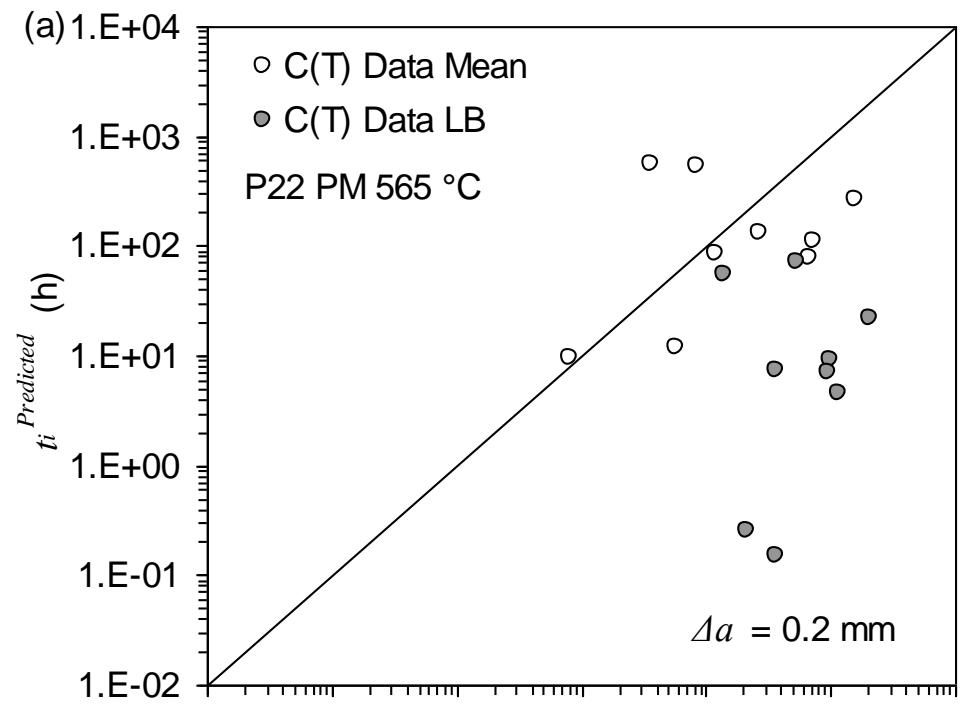

1.E-02 1.E-01 1.E+00 1.E+01 1.E+02 1.E+03 1.E+04

$t_{i}{ }^{E x p}$ (h)

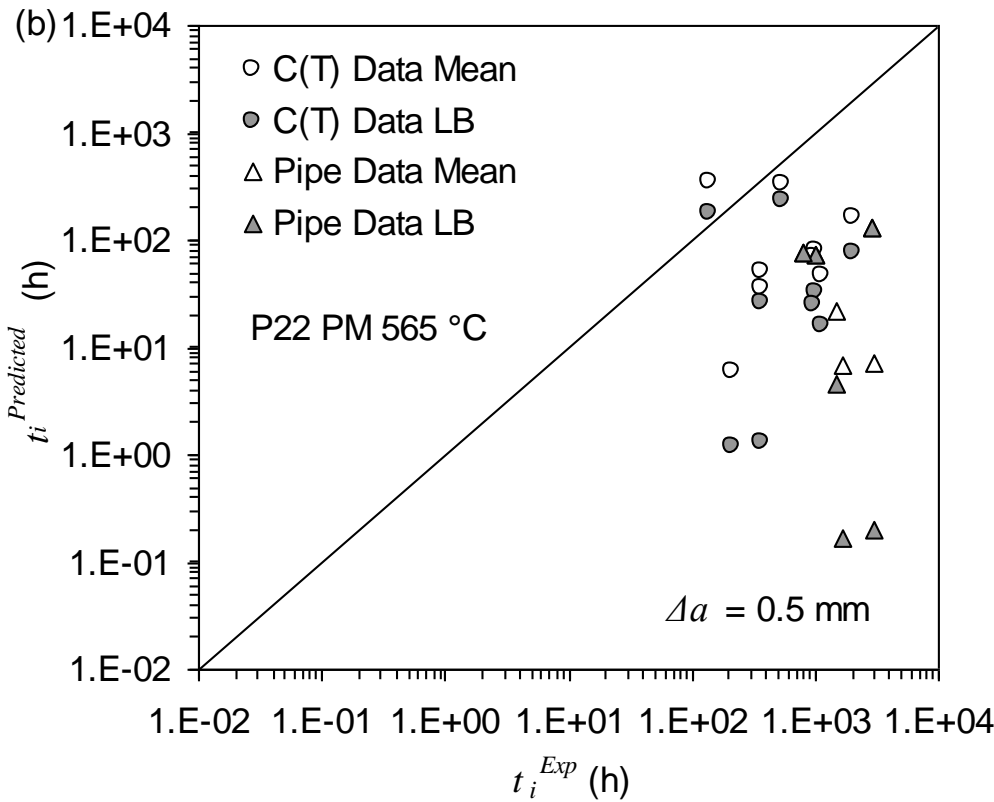

Figure 14: Comparison of the predicted and experimentally determined $\mathrm{CCl}$ times from tests on homogenous PM C(T) specimens and pipe components of P22 steel at $565{ }^{\circ} \mathrm{C}$ for (a) $0.2 \mathrm{~mm}$ and (b) $0.5 \mathrm{~mm}$, using mean and lower bound $K_{c}^{\text {mat }}$ values. 

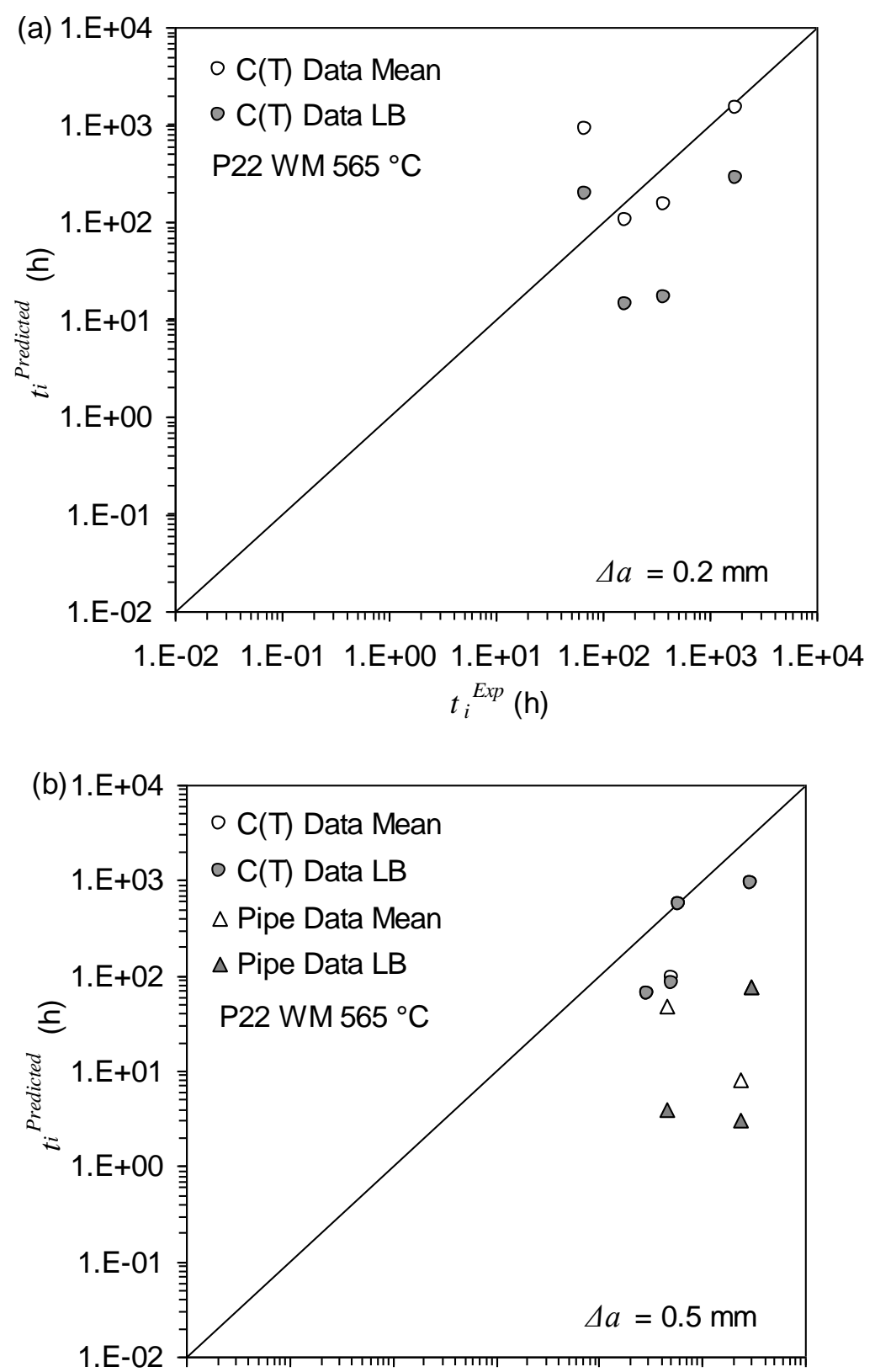

1.E-02 1.E-01 1.E+00 1.E+01 1.E+02 1.E+03 1.E+04

$t_{i}^{E x p}(\mathrm{~h})$

Figure 15: Comparison of the predicted and experimentally determined $\mathrm{CCl}$ times from tests on $\mathrm{C}(\mathrm{T})$ weldment specimens and welded pipe components of $\mathrm{P} 22$ steel at $565{ }^{\circ} \mathrm{C}$ for (a) $0.2 \mathrm{~mm}$ and (b) $0.5 \mathrm{~mm}$, using mean and lower bound $K_{c}^{\text {mat }}$ values. 